داود عبد الملك الحلدابي فتيحة العسري

المجلد الثاني عشر العدد (22) 2021م المئ المبري

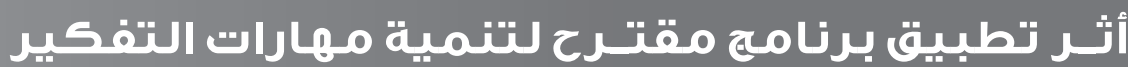

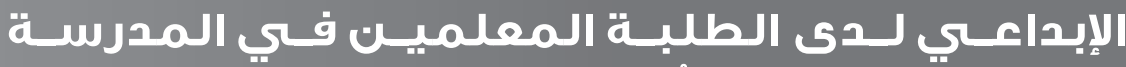

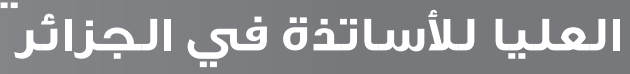

الاستلام:20 /20/ديسـمبر/2020/2020

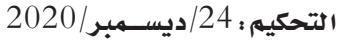

القبــول: 2020/20/ديسيـمبـ/24

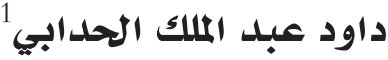

فتيحة العسري|(2،

(c) 2021 University of Science and Technology, Yemen. This article can be distributed under the terms of the Creative Commons Attribution License, which permits unrestricted use, distribution, and reproduction in any medium, provided the original author and source are credited.

C 2021 جامعــة العلوم والتكنولوجيا، اليمن. يمكن إعادةٌ اســتخدام المادةٌ المنشــورةٌ حســبـ رخصة مؤسسة المشاع الإبلاعي شريطة الاستشهاد بالمؤلف والمأجلة. 


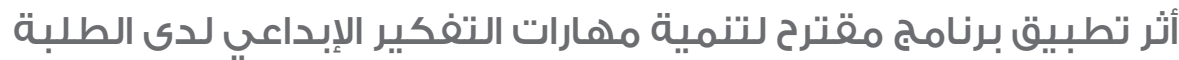

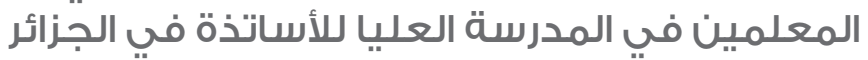

الملخص:

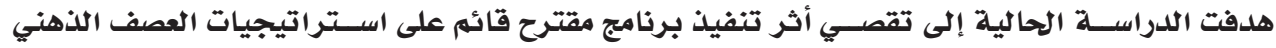

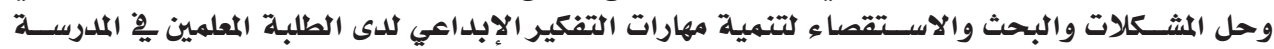

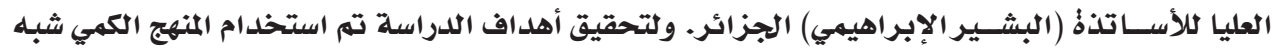

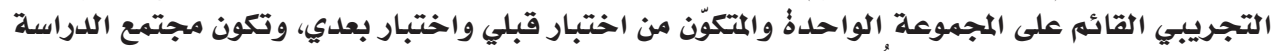

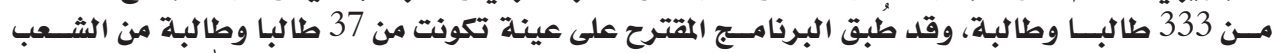

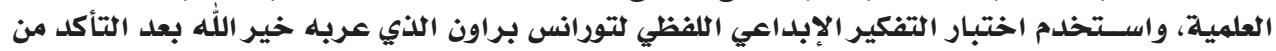

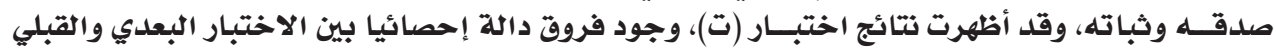

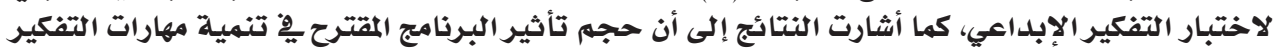

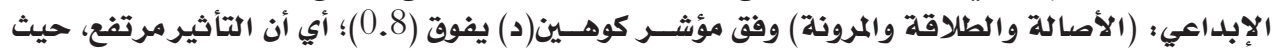

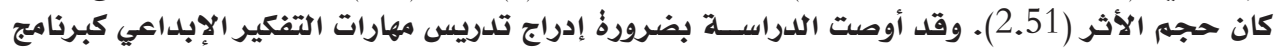

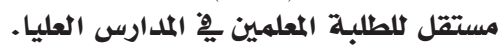
الكلمات المفتاحية : البرنامج، التفكير الإبداعي، مهارات التفكير الإبداعي. 


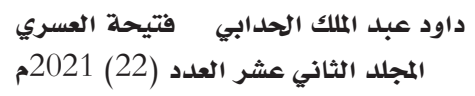

\title{
The Effect of Implementing a Proposed Program for Developing Creative Thinking Skills among Student-Teachers at the Higher Teachers' Institute, Algeria
}

\begin{abstract}
:
The study aimed to investigate the impact of implementing an improved program for developing creative thinking skills among student-teachers at the Higher Teachers' Institute (Bashir Al Ibrahimi), Algeria. The quantitative, semiexperimental, one-group approach was used, involving a pre-and post-test. The developed program was applied to a sample of 37 male and female students from science classes. The verbal creative thinking test of Torrance Brown, which was translated to Arabic by Khair Allah, was used after confirming its validity and reliability. The results of the $(T)$ test showed that there were statistically significant differences between the post-test and the pre-test of the creative thinking test. The results also indicated that the effect of the developed program in developing creative thinking skills (originality, fluency and flexibility) according to the Cohen indicator (D) exceeded (0.8), which means that the effect was high, as the volume of the effect was (2.51). The study recommended that teaching creative thinking skills should be included as an independent program for student-teachers in higher institutes.
\end{abstract}

Keywords: program, creative thinking, skills of creative thinking. 


\section{المقدمة: إنمية}

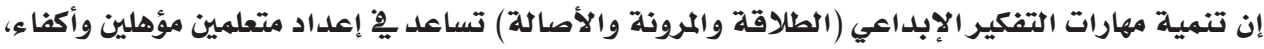

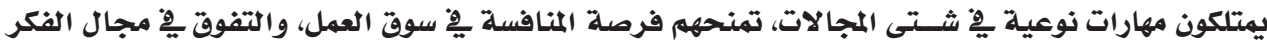

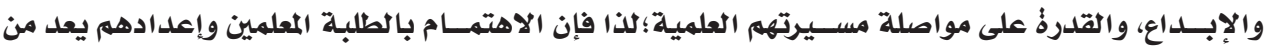

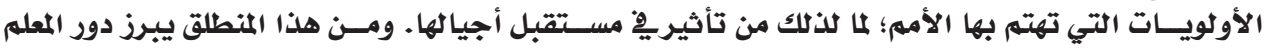

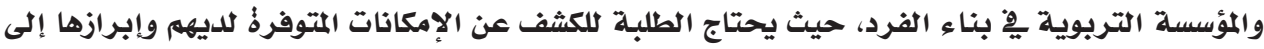

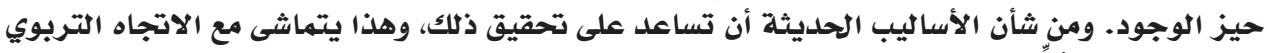

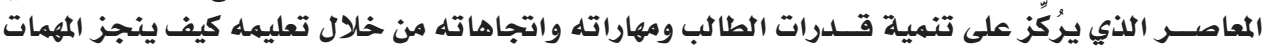

وفق تلك المهارات.

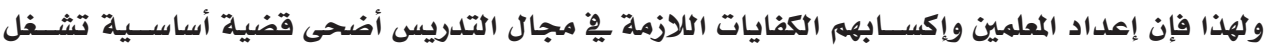

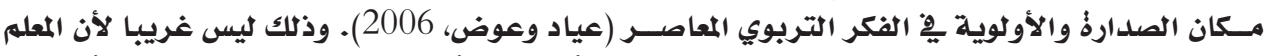

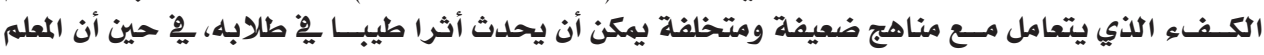

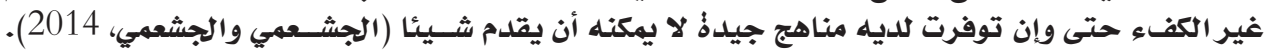

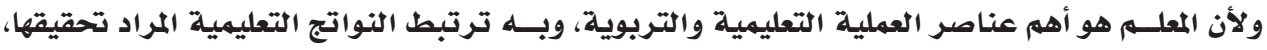

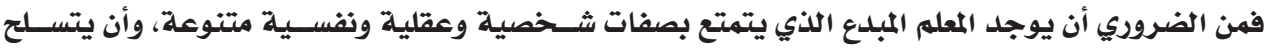

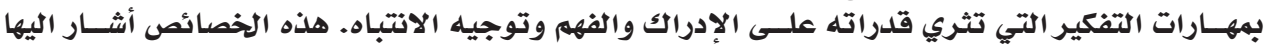
الفير Molès ،Basset-Séguin ،Mils

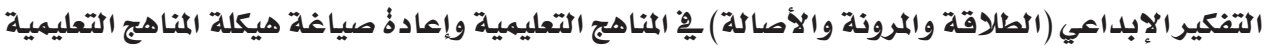

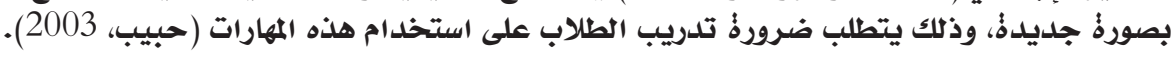

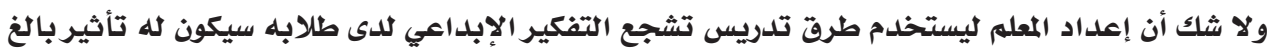

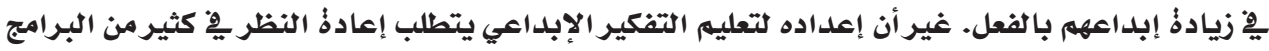

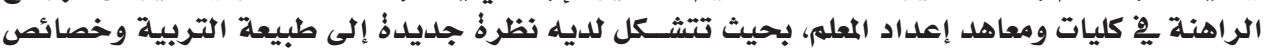

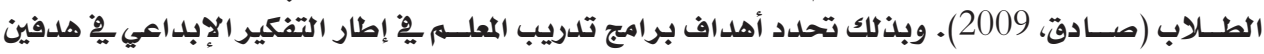

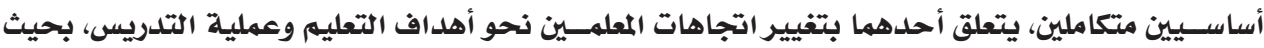

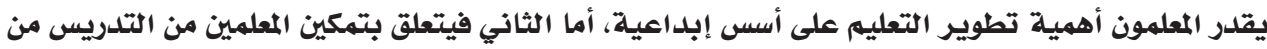

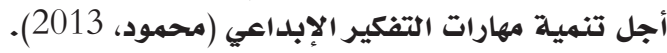

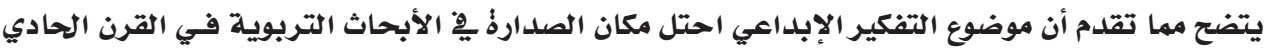

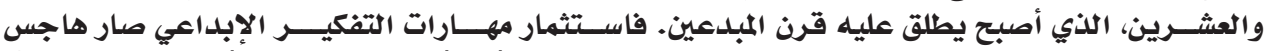

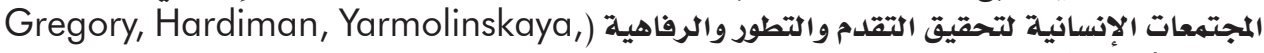

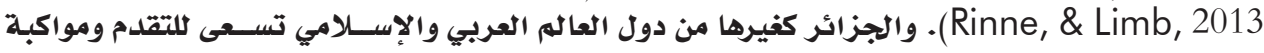

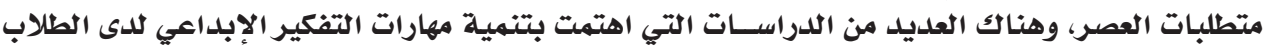

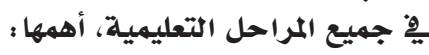

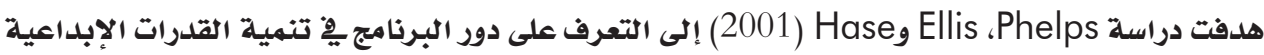

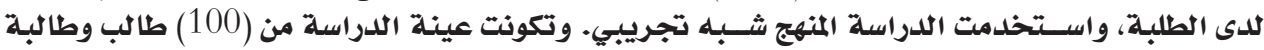

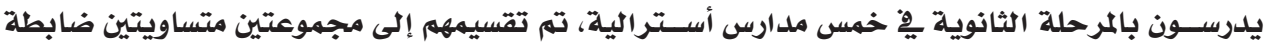

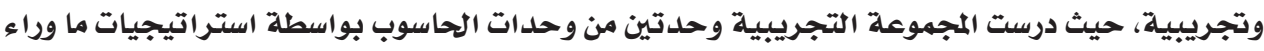

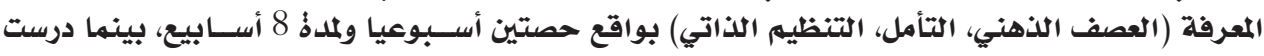

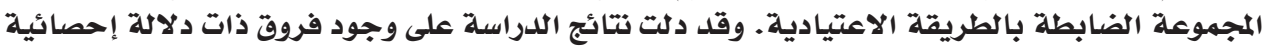

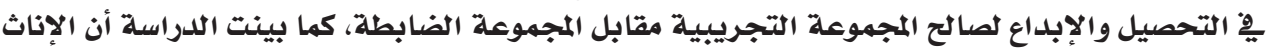

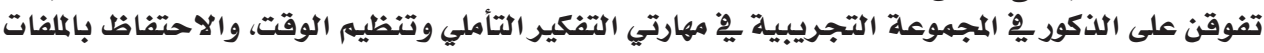

الإكترونية. 


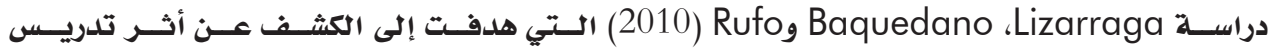

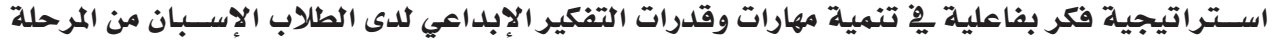

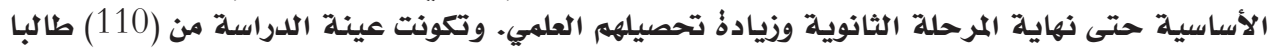

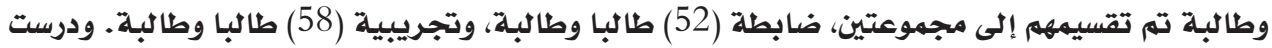

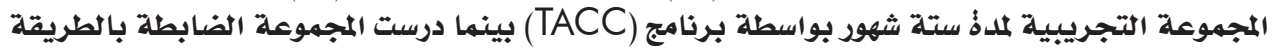

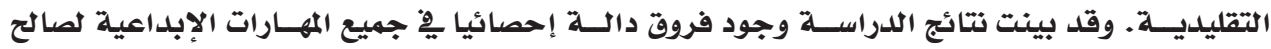

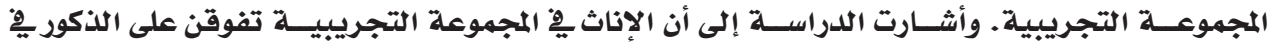

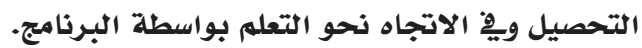

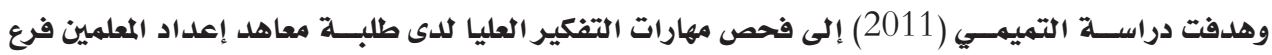

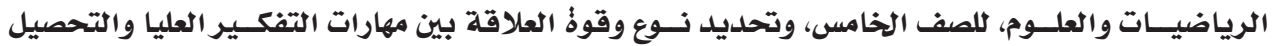

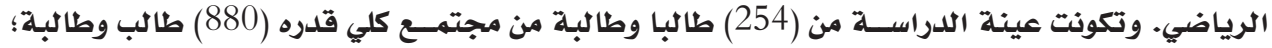

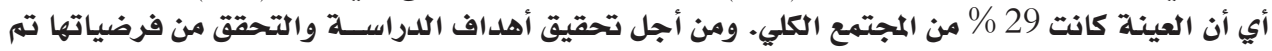

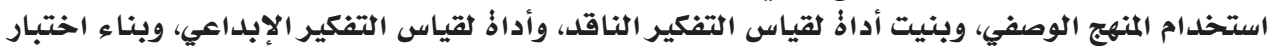

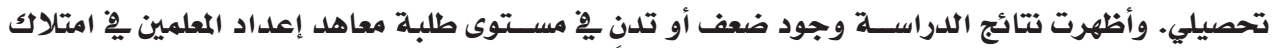

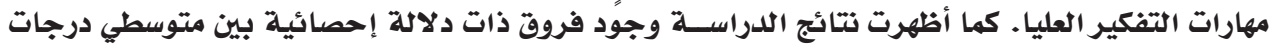

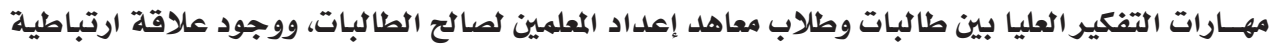
موجبة ضعيفة بين مهارات التفكير العليا والتحصيل التيات الرياضي.

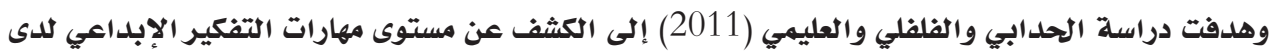

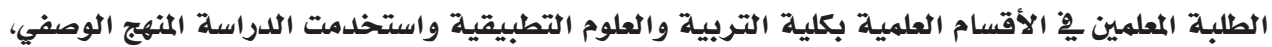

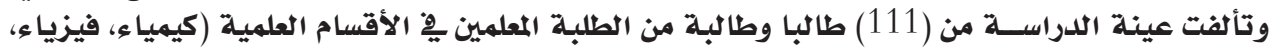

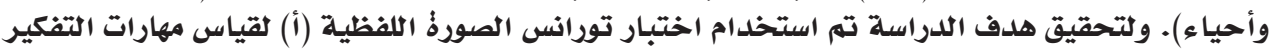

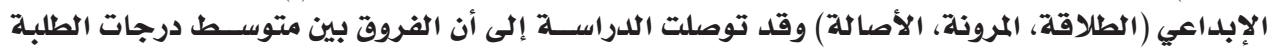

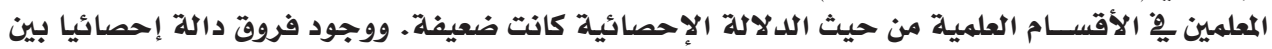

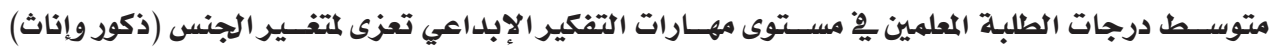

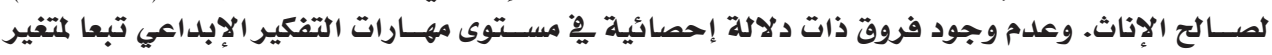
التخصص (كيمياء، فيزياء، وأحياء).

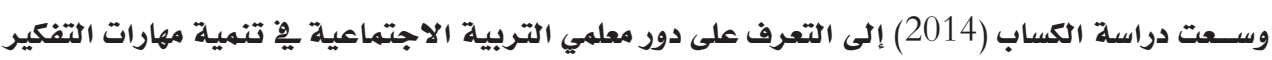

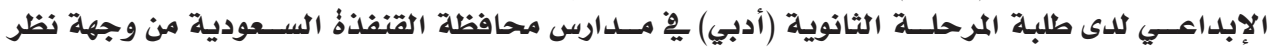

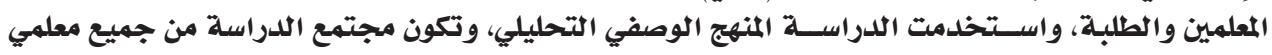

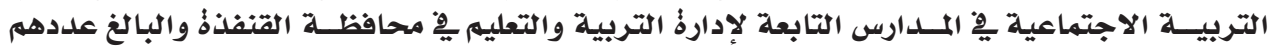

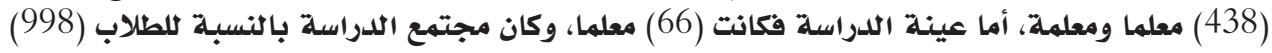

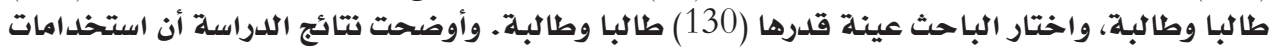

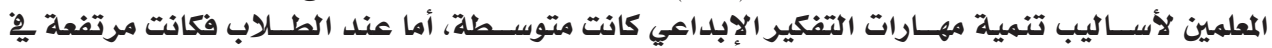

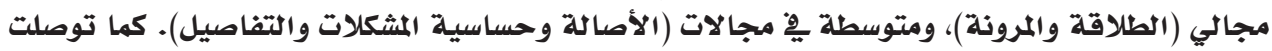

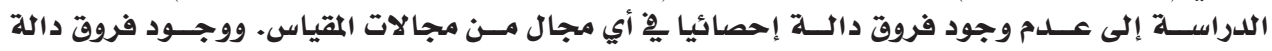

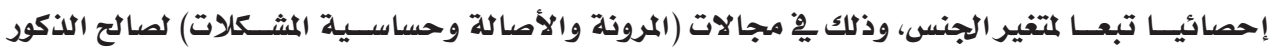

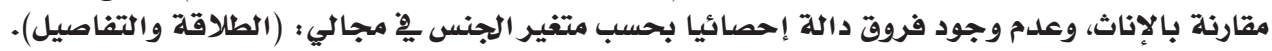

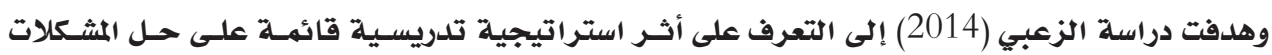

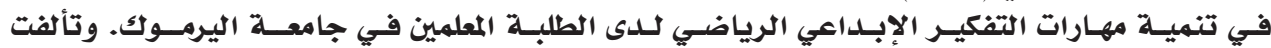

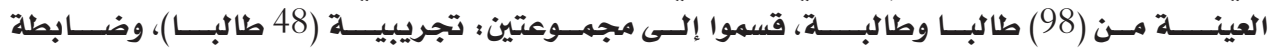




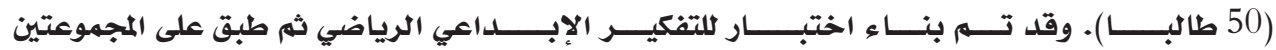

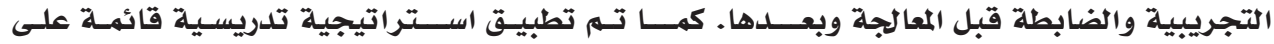

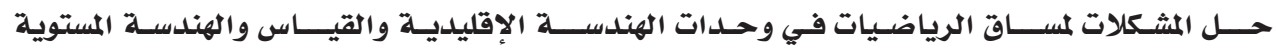

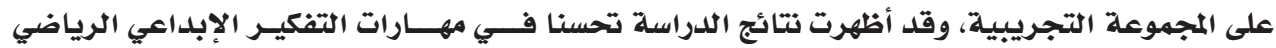

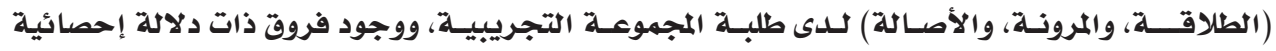

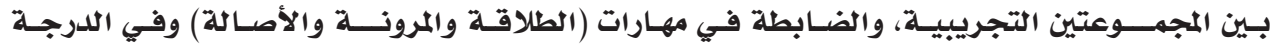

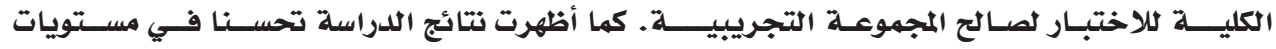

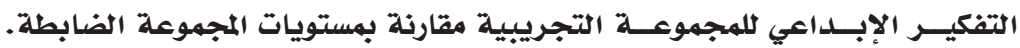

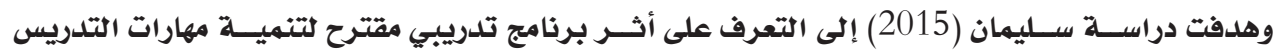

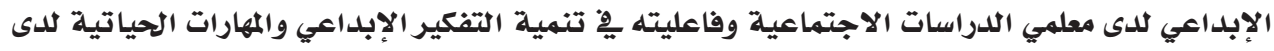

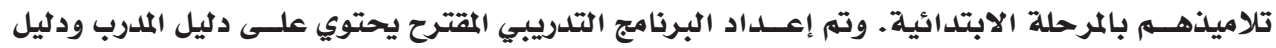

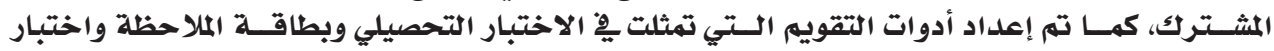

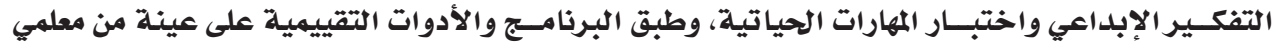

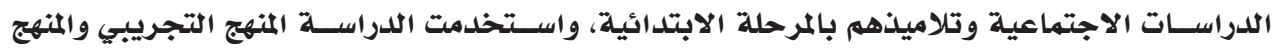

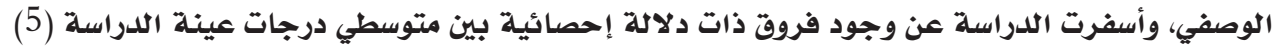

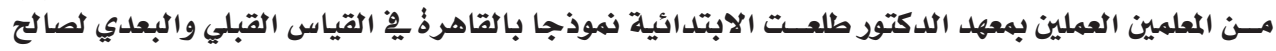

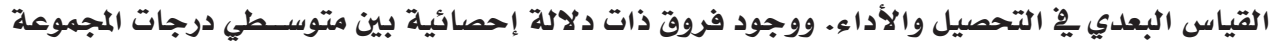

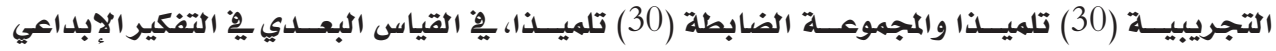

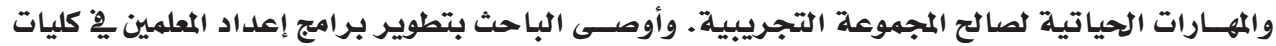

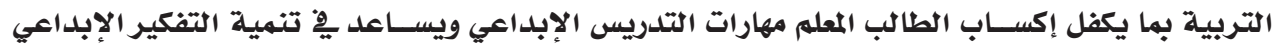

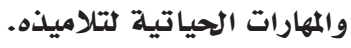

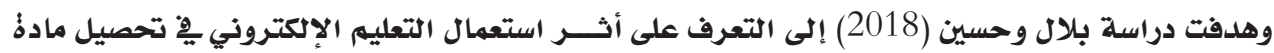

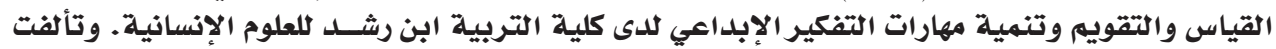

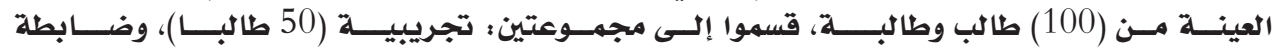

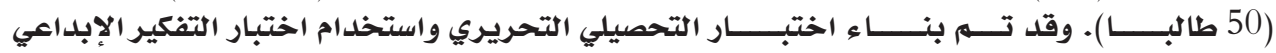

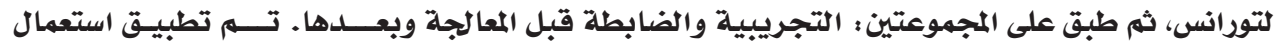

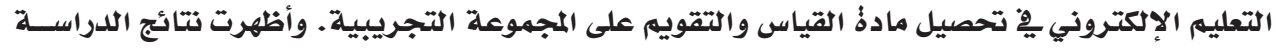

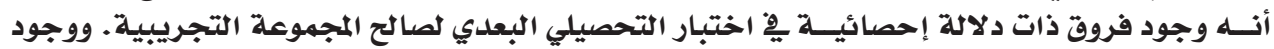

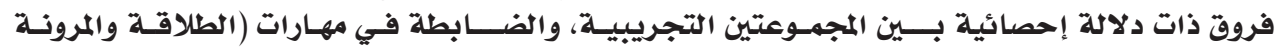

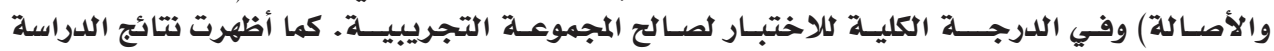

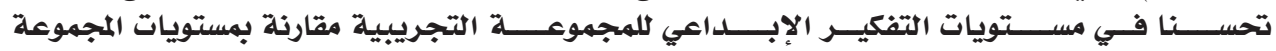

الضابطة.

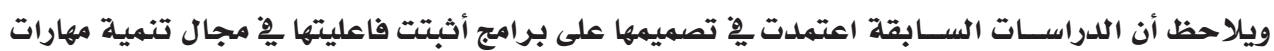

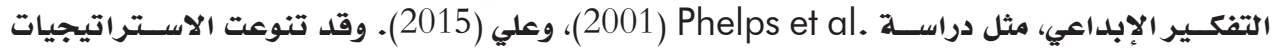

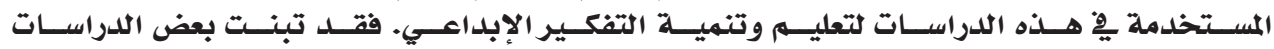

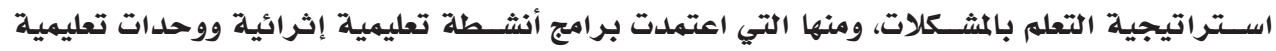

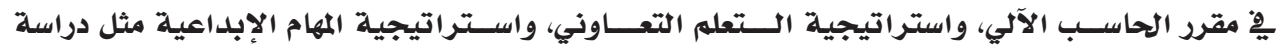
دواس Lizarraga et al.

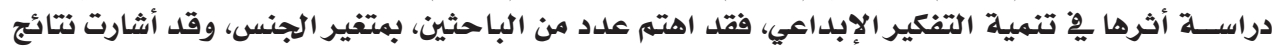

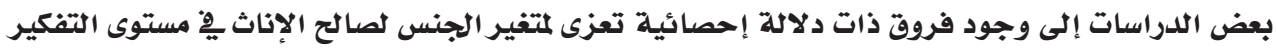
الإبلداعي ومنها دراســة كل من التهيهي (2011)، الحدابي وآخرون (2011)، و و . Phelps et al (2001)، 


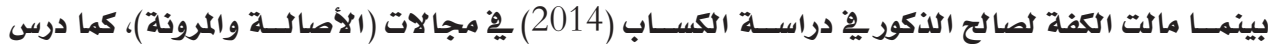

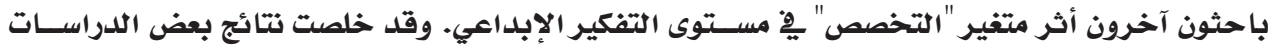

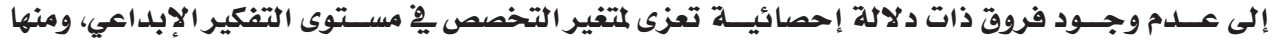

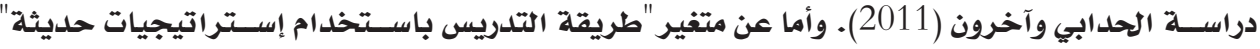

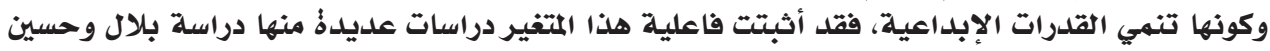
.(2018)

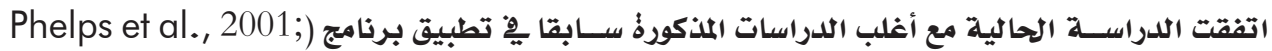
من الـizarraga et al., 2010

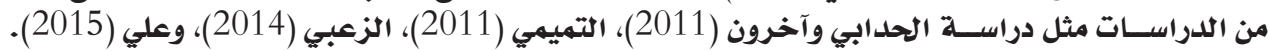

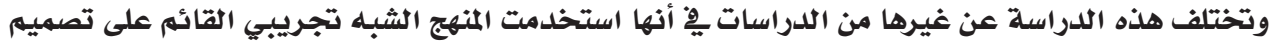

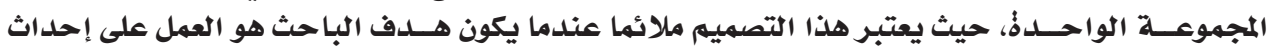
تغييرِِ نهط السلوك أو ِِّ بعض العمليات العقلية (الكاظمي، 2012)، ويكون التغيير تغييرا حقيقيا.

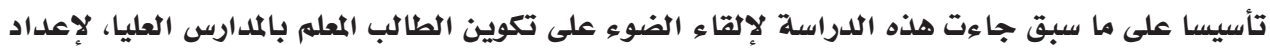

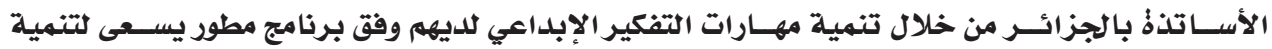

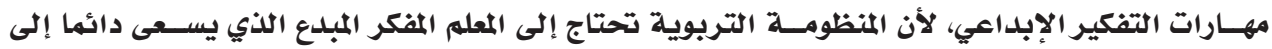

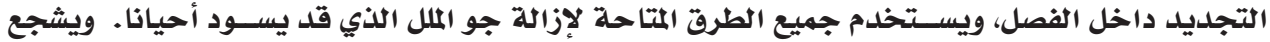

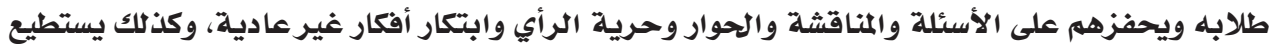

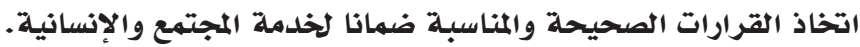
مشكلة الدراسة وأسئلتها:

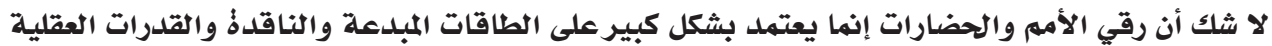

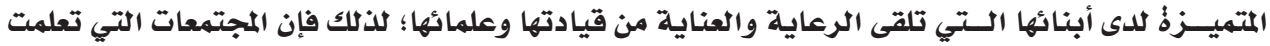

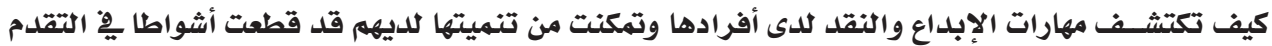

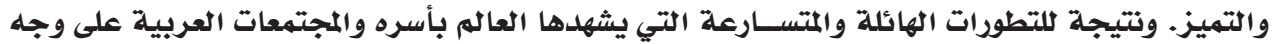

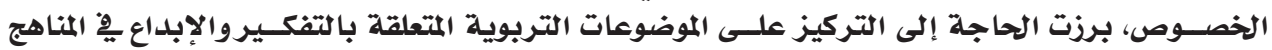

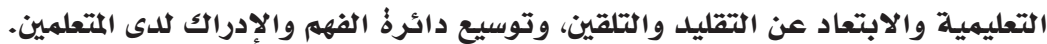

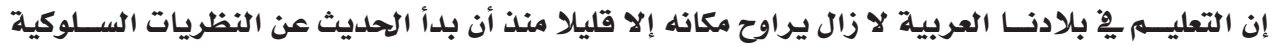

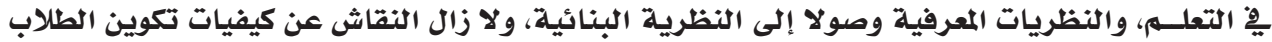

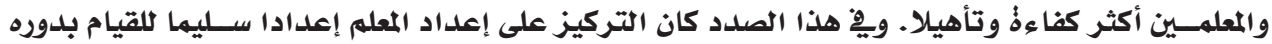

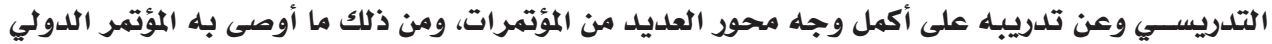

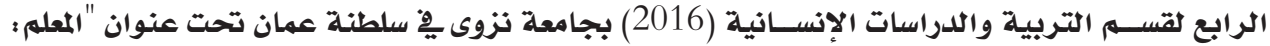

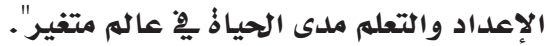

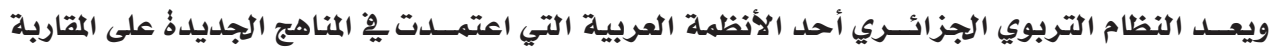

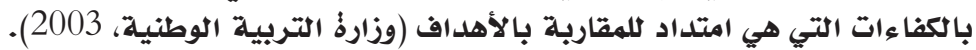

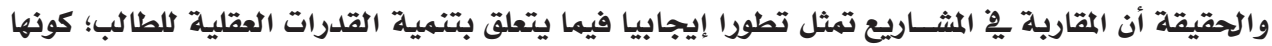

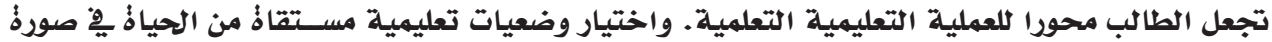

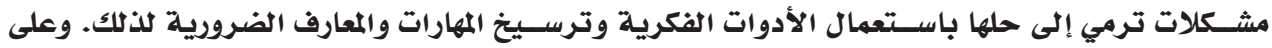

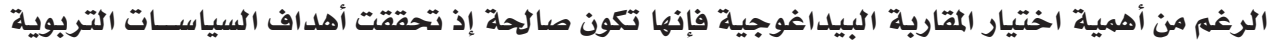

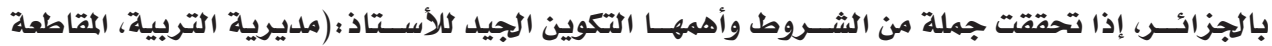

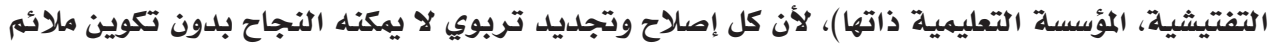




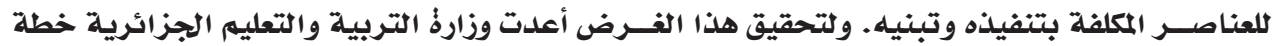

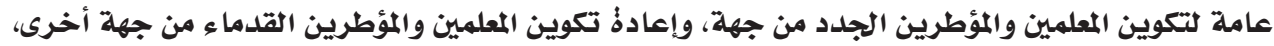

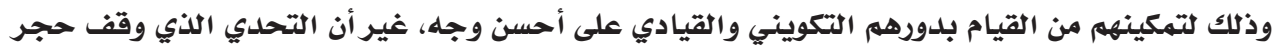

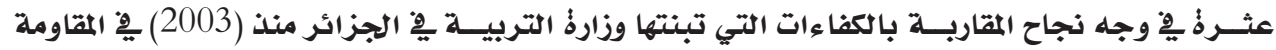

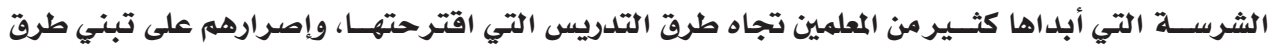

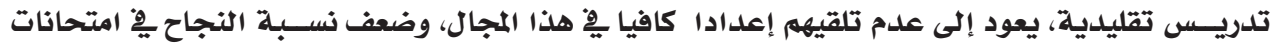

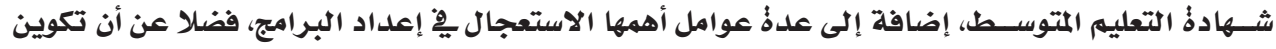

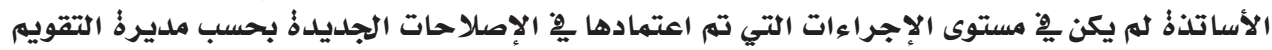

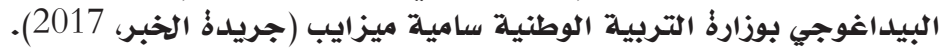

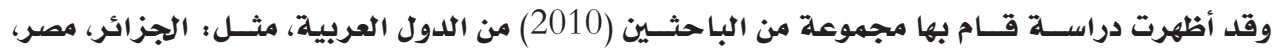

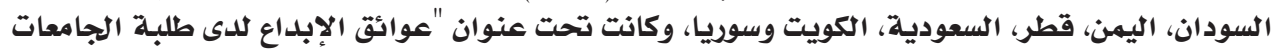

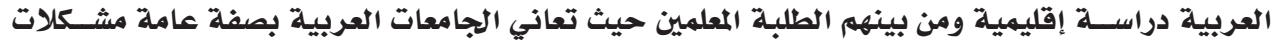

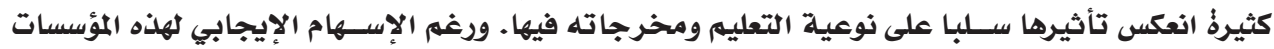

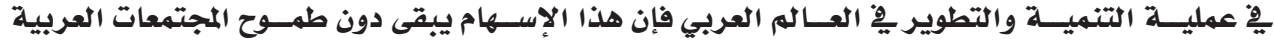

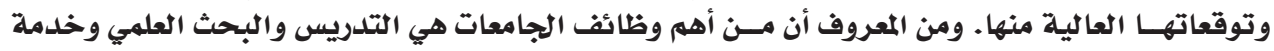

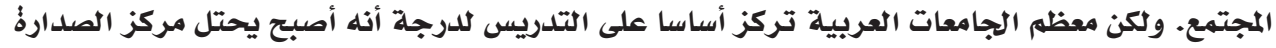

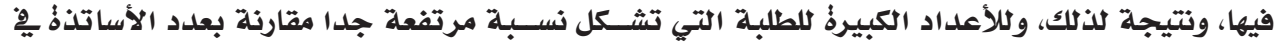

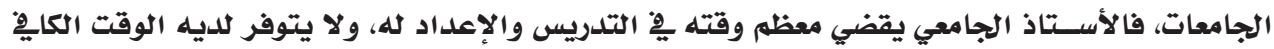

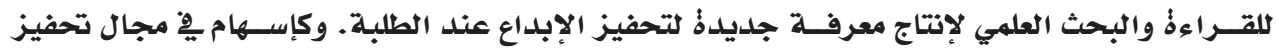

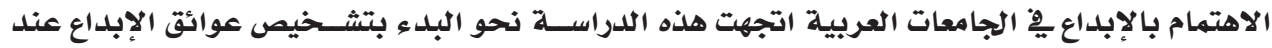

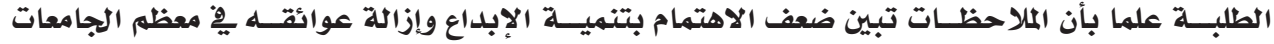

العربية.

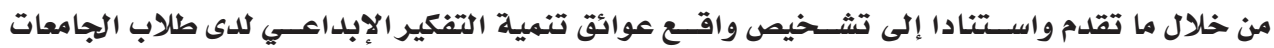

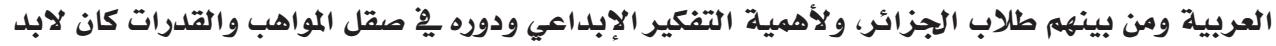

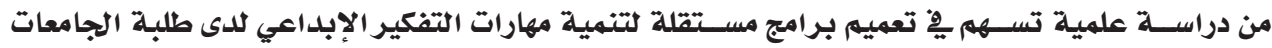

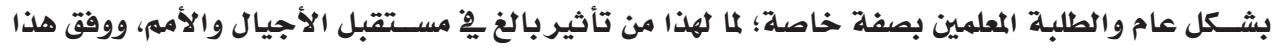

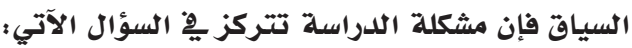

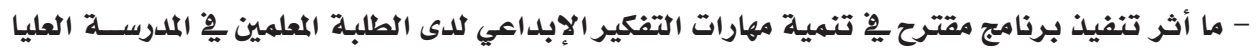

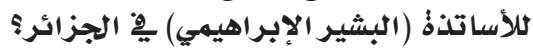

هدف الدراسة:

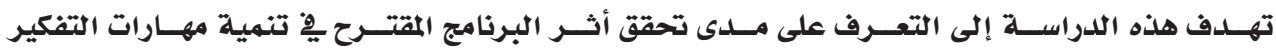

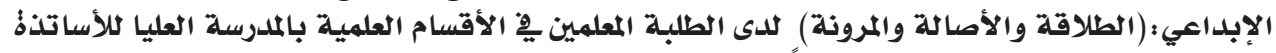

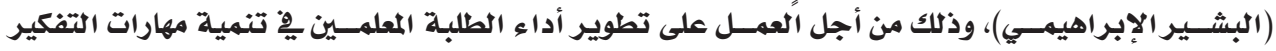

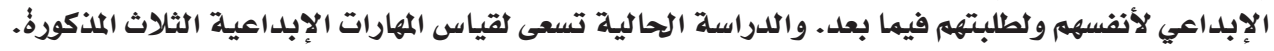

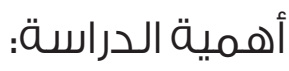

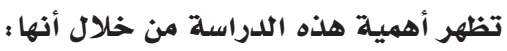

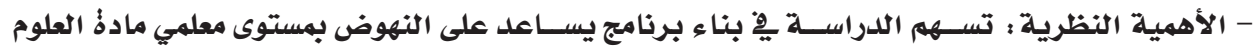

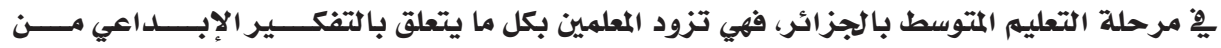

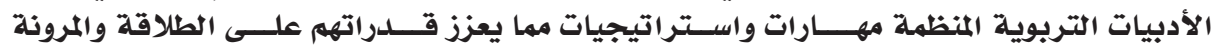
والأصالة للوصول إلى أفضل الحلودل المثلة مهارات والمكنة. 
داود عبد الملك الحدابي فتيحة العسري

المجلد الثاني عشر العدد (22) 2021م المئ المرئ

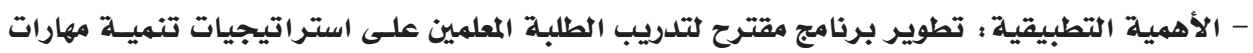

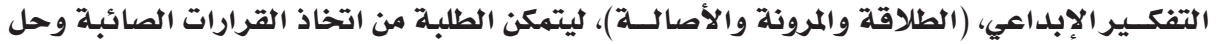

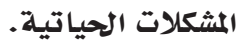

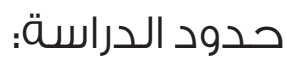

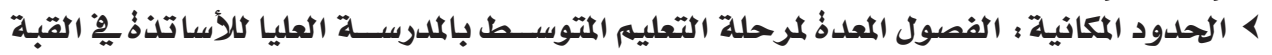

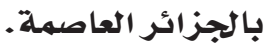

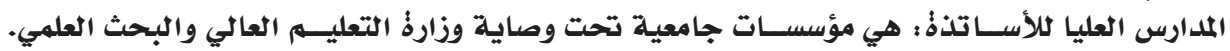

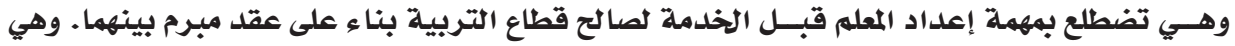

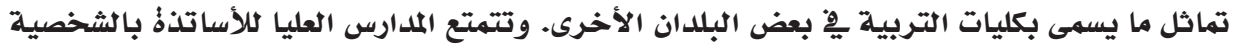

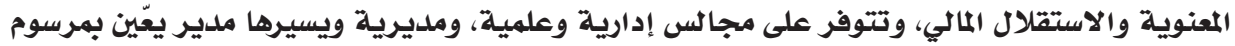

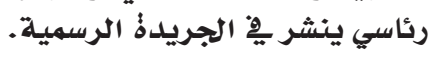

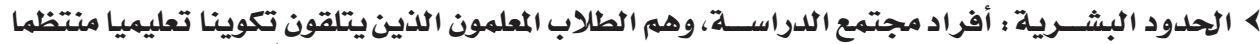

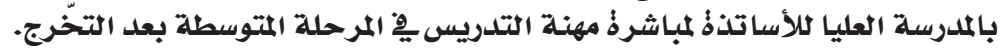

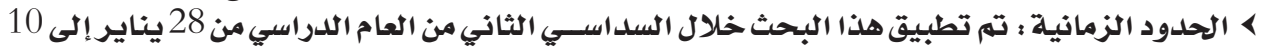

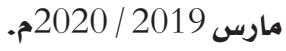

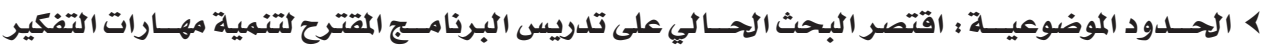

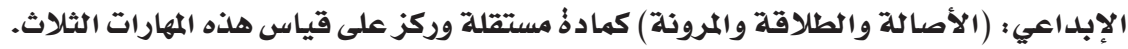

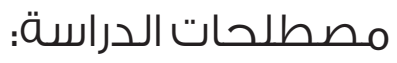

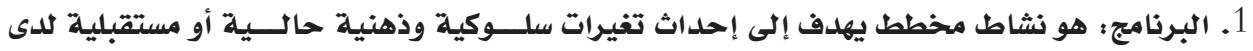

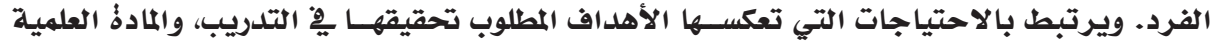

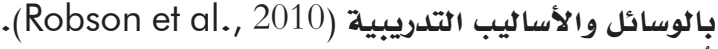

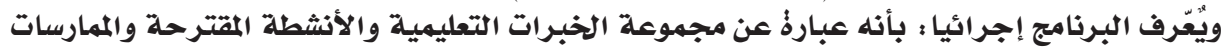

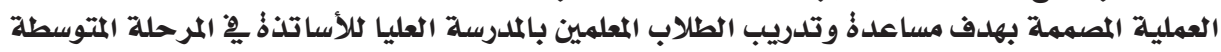

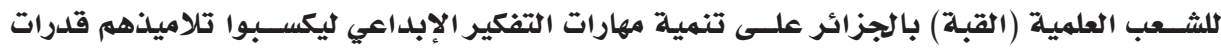
التفكير: وتنميية مهاراته.

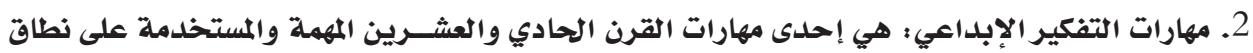

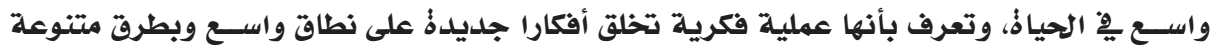

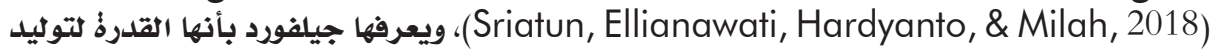

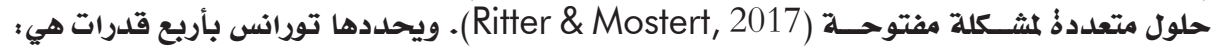
الطلاقة والمرونة والأصالة والتفاصيل (Torrance, 1965; Kolloff \& Feldhusen, 1984).

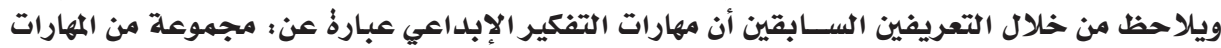

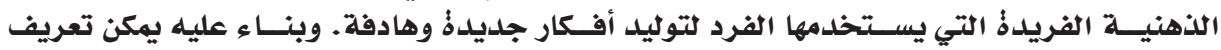

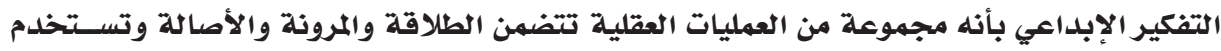
كلإتيان بالجديد من الأفكار.

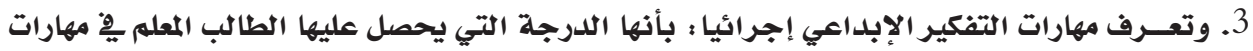

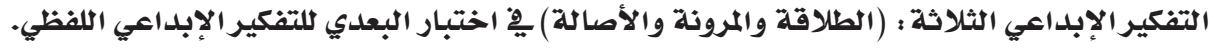

$$
\text { الإطار النظري: }
$$

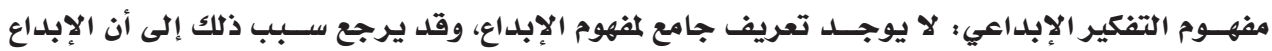

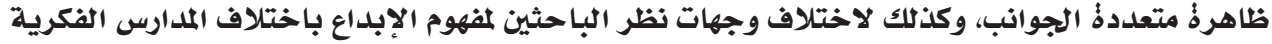
التي ينتهون إليها (الطيطي، 2007). 
تعريف التفكير الإبلاعي باعتباره عملية إبداعية ؛

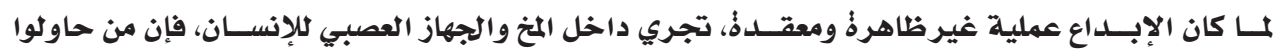

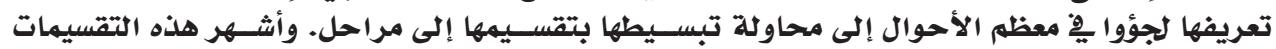

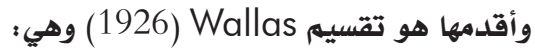

1. مرحلة الإعداد : التي تتضمن دراسة المشكلة بالاطلاع والتجربة والخئة والخبرة.

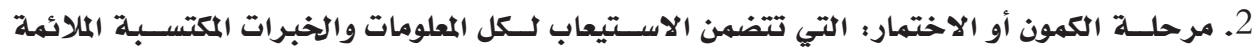
وهضمها أو تمثيلها عقليا.

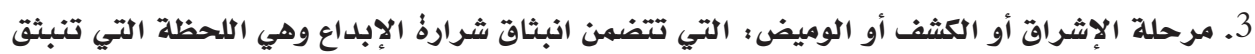
فيها الفكرةٌ الجديلدة. 4. مرحلة التحقق : التي تتضمن الاختبار التجريبي للفكرةٌ المبتكرةٌ وتقييهها (نوفل وأبو جادو، 2017). تعريف التفكير الإبداعي باعتباره إنتاجا إبداعيا (Production) :

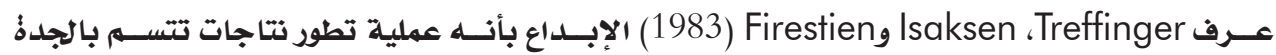

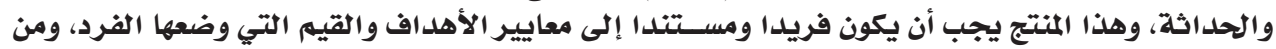

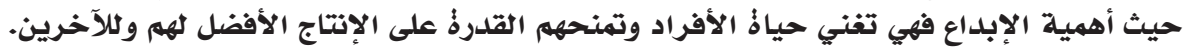
تعريف التفكير الإبداعي باعتبار السمات الشخصية ؛

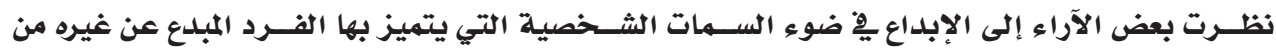

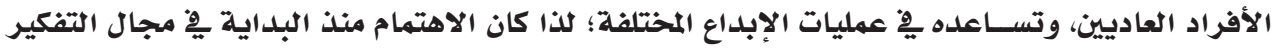

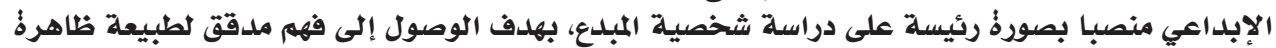

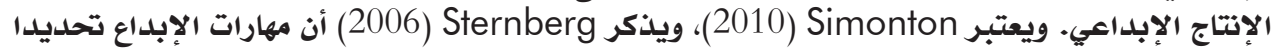

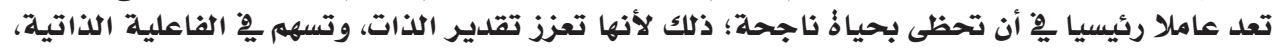

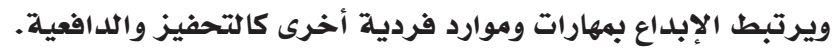
مهارات التفكير الإبلداعي:

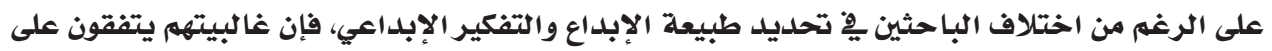

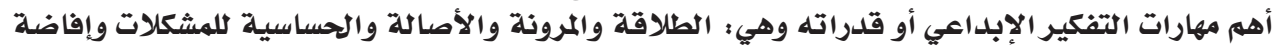

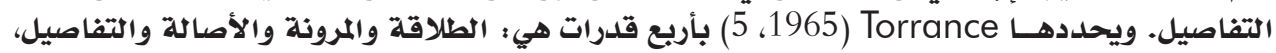
وتوضح ذلك Folloff و و Feldhusen (1984، 33 ) كالآتي:

أولا : الطلاقة (Fluency) وهي تعني إنتاج عدد كبير من الأفكار، واكتشـاف حلول أو التوصل إلى بدائل

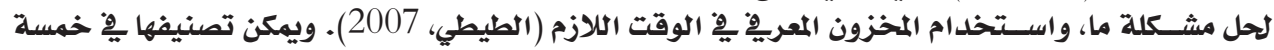
أنواع هي:

1. الطلاقة اللفظية : وتتمثل بِّ القدرةٌ على إنتاج أعداد كبيرةٌ من الألفاظ.

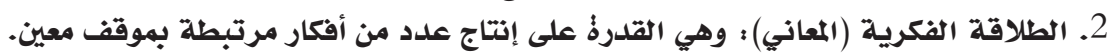

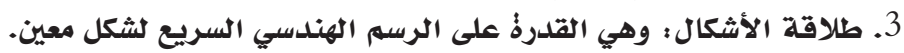

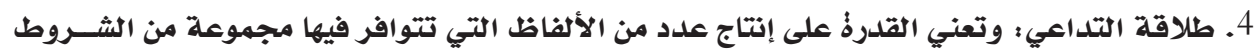
من حيث المعنى. 5. الطلاقة التعبيرية : ويعني بها القدرةٌ على صياغة الأفكار ِِّ عبارات مفيدة. 


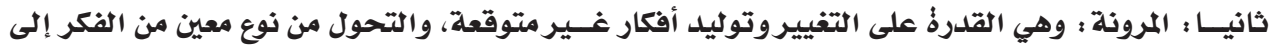

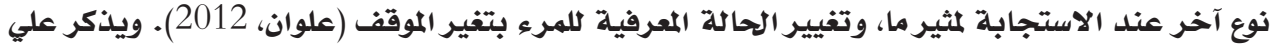

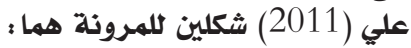

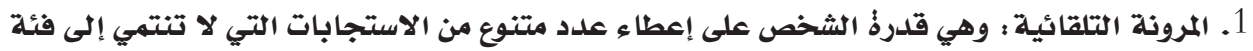

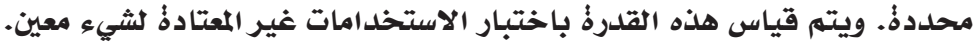

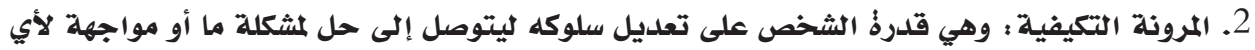

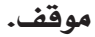

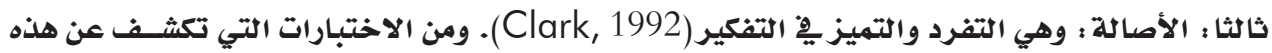

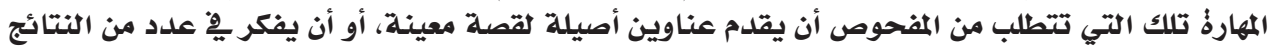

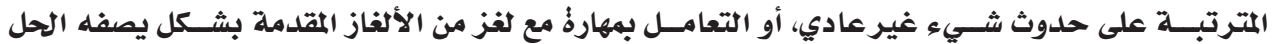
(جروان، 2013).

$$
\text { منهج الدراسة الدراسة و إجـراءاتها: }
$$

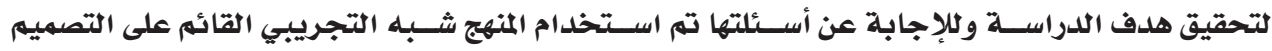

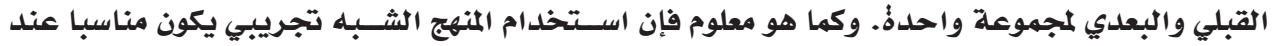

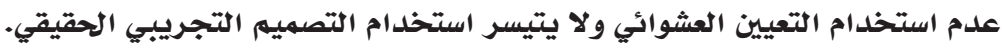
تصميم التجربة :

\begin{tabular}{|c|c|c|}
\hline الاختبار البعدي & المعالجة التجريبية (المتغير المستقل) & الاختبار القبلي \\
\hline اختبار التفكير الإبداعي & تطبيق البرنامج المقترح لتنمية مهارات التفكير الإبداعي & اختبار التفكير الإبداعي \\
\hline
\end{tabular}

جدول (1): تصميم التجربة للمجموعة التجريبية الواحدة:

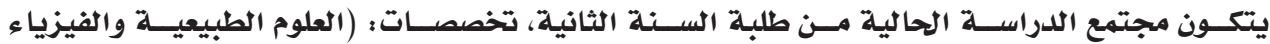

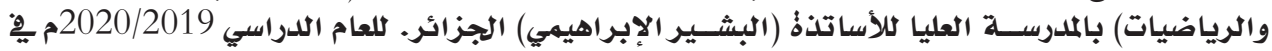

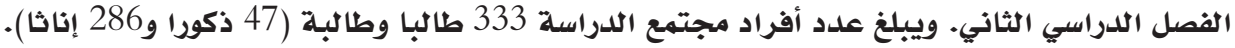
عينة الدراسة :

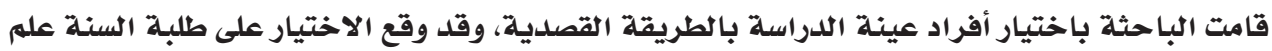

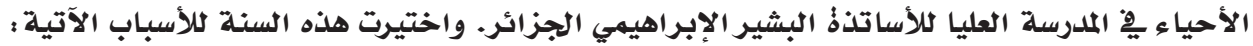

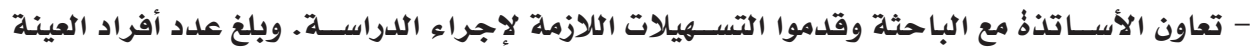

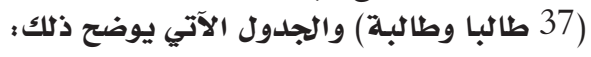

\begin{tabular}{|c|c|c|c|c|c|}
\hline الإناث & الذكور & عينـة الدراسلة & الإناث & الذكور & مجتهع الدراسة \\
\hline 31 & 6 & 37 & 286 & 47 & 333 \\
\hline
\end{tabular}

جدول (2): توزيع أفراد عينة الدراسة دولة

أدوات اللدراسة ؛

استخلدمت الدراسة الحالية :

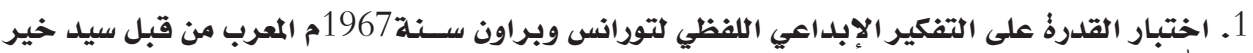
الله سنة 1981م، وهو يتألف من قسمين الإبل اعي الفئ 


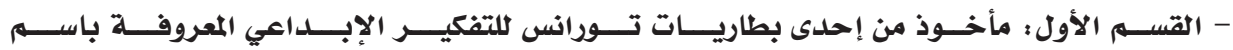

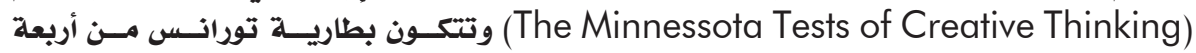
اختبارات فرعية هي: الاستعمالات، المترتبات، المواقف، التطوير والتحسين.

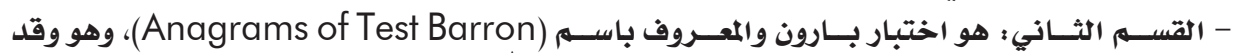

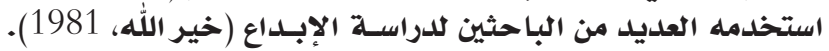

$$
\text { إجـراءات الدراسة الميدانية: }
$$

الدراســـة الاســــلاعية : أجريت هذه الدراســة من أجل التحقق من الخصائص السـيكومتريـة لاختبـار التفكير الإبداعي.

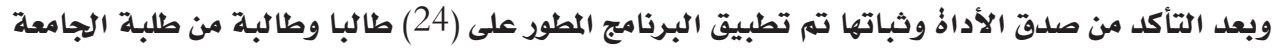

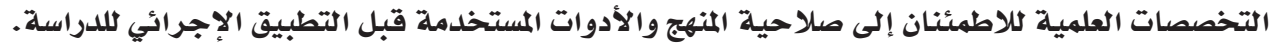

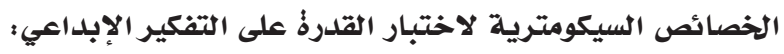

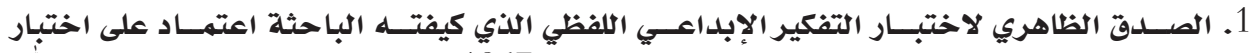

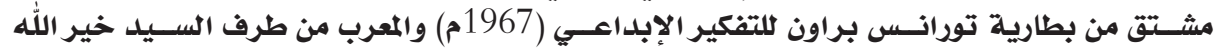

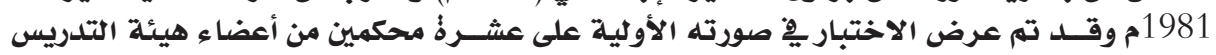

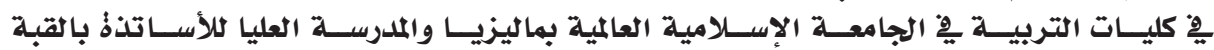

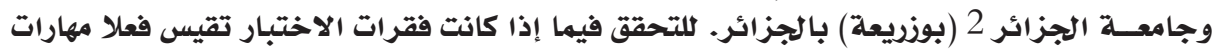

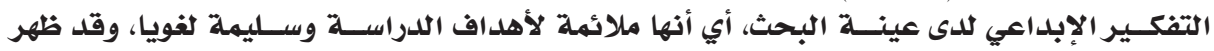

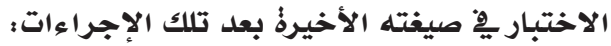

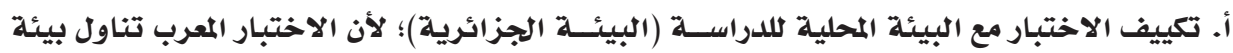

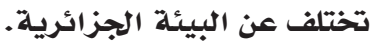

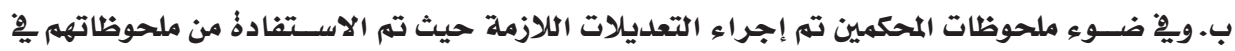
الأمور الآتية : • تغييرِيْ جزء الاستعمالات علبة الصفيح بالقارورةٌ البلاستيكية للمشروبات الغازية.

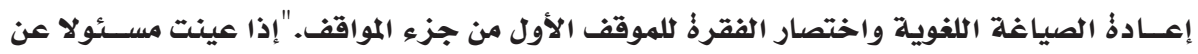

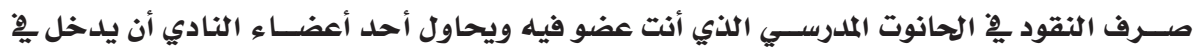

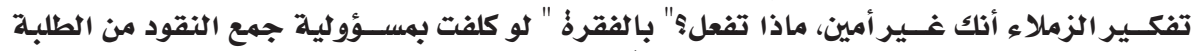

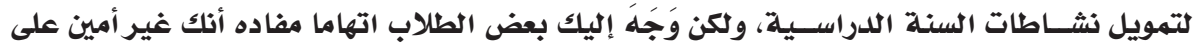

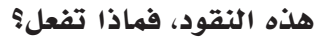

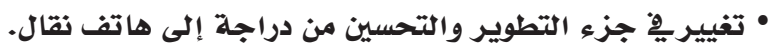

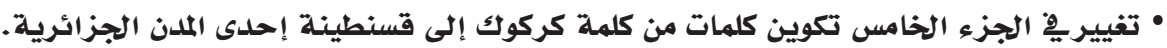

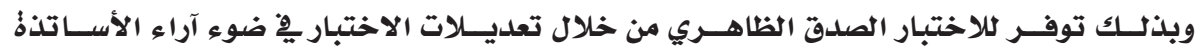
المحكمين.

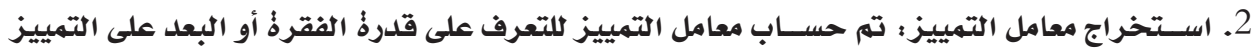

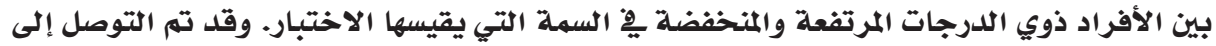

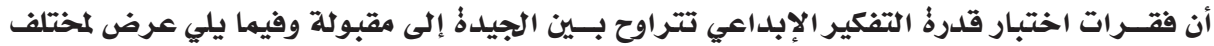

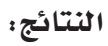


جدول (3): نتائج حساب معامل التمييز لفقرات اختبار قدرةٌ التفكير الإبداعي

\begin{tabular}{|c|c|c|c|c|}
\hline \multirow{2}{*}{ القرار الإحصائي } & \multirow{2}{*}{ معامل تمييز الفقرةٌ } & \multicolumn{2}{|c|}{ إجابات الأفراد على الاختبار } & \multirow{2}{*}{ فقرات الاختبـار } \\
\hline & & المجموعة الدنيا & المجموعة العليا & \\
\hline الفقرةٌ مقبولة & $\% 34.07$ & 304 & 533 & الطلاقة \\
\hline الفقرةٌ مقبولة وتميز جيد & $\% 49.37$ & 59 & 138 & 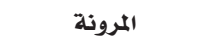 \\
\hline الفقرةٌ مقبولة وتميز جيدا & $\% 47.54$ & 67 & 280 & الأصالة \\
\hline الاختبار مقبول & $\% 37.08$ & 439 & 884 & الدرجة الكلية \\
\hline
\end{tabular}

3. الاتســاق الداخلي : تم حساب الصدق بطريقة الاتسـاق الداخلي بين القدرة التي يقيسها الاختبار

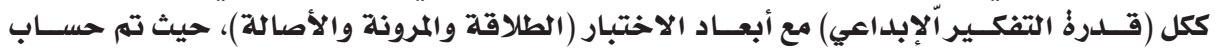

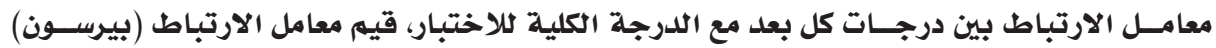

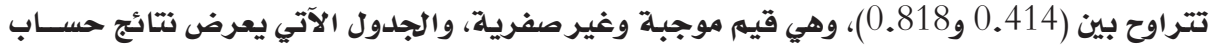

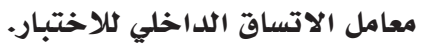

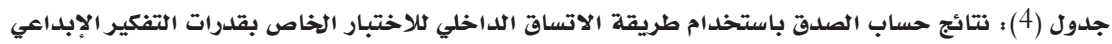

\begin{tabular}{|c|c|c|c|c|}
\hline بعد الأصالة & بعل المرونة & بعد الطلاقة & اختبار قدرةٌ التفكير & معامل الارتباط بيرسون \\
\hline 0.818 & 0.638 & 0.761 & 1 & اختبار قدرةٌ التفكير الإبداعي \\
\hline 0.484 & 0.481 & 1 & & بعد الطلاقة \\
\hline 0.414 & 1 & & & بعد المرونة \\
\hline 1 & & & & بعد الأصالة \\
\hline
\end{tabular}

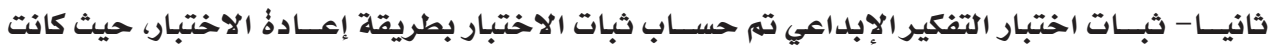

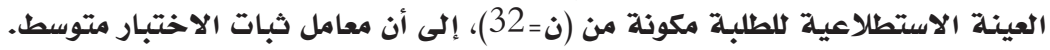

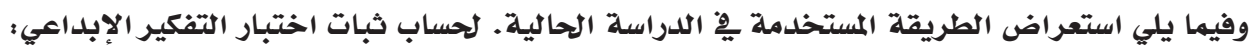

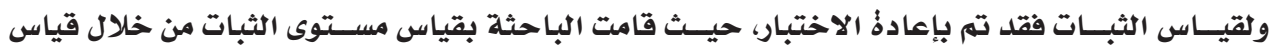

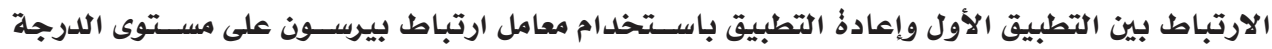

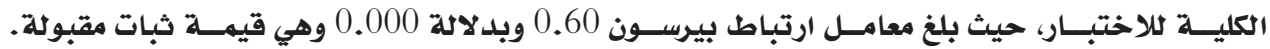
والجدول (5) يوضح ذلك.

جدول (5): مستوى ثبات اختبار التفكير الإبداعي من خلال قياس الارتباط بين التطبيق الأول وإعادة التطبيق

\begin{tabular}{|c|c|c|}
\hline مستوى الدلالة & درجة الحرية & معامل بيرسون \\
\hline 0.000 & 30 & 0.60 \\
\hline
\end{tabular}

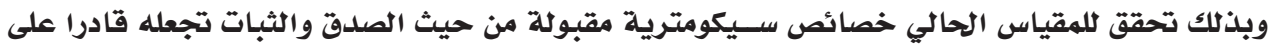

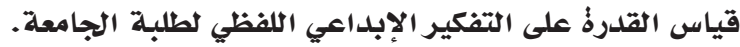

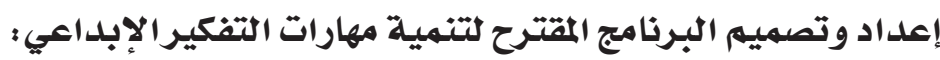
لقد تم إعداده وتصميمه وفق الخطوات الآتية :

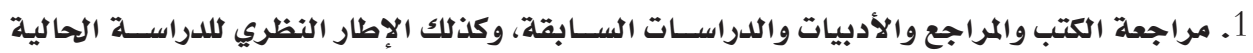
كلاطلاع على مفهوم مهارات التفكير الإبداعي.

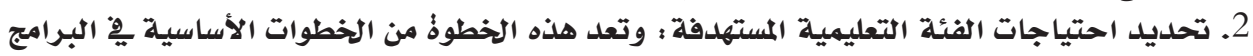

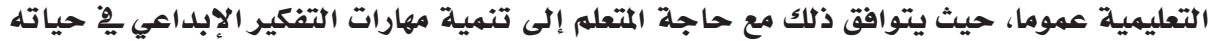

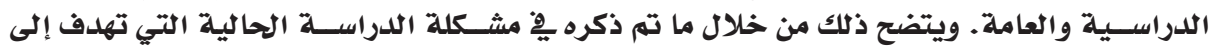

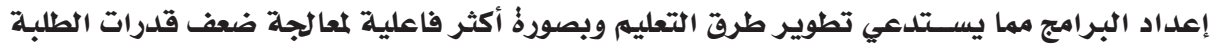


3. مراجعــة معايير تطويــر برنامج لتنهية مهـارات التفكير الإبلداعي وعلى أثرهـــا تم إعداد البرنامج

المقترح.

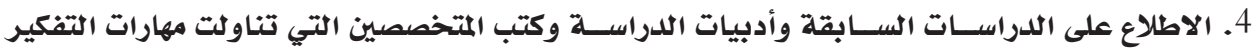

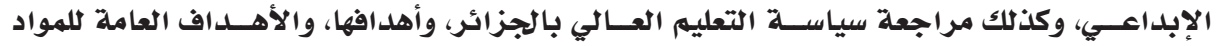

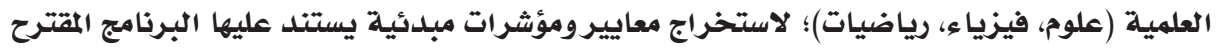

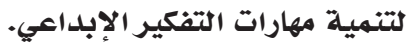

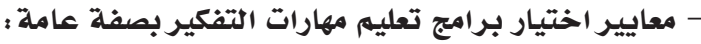

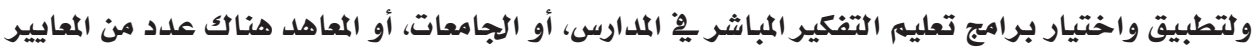

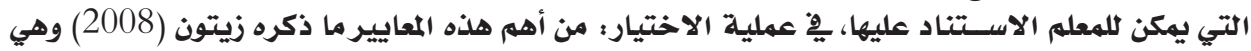
كالآتي : النئ

1. وجود أساس نظري للبرنامج، أي يكون مبنيا على أفكار نظرية تتعلق بالتفكير وتعليمه. 2. وضوح مهارات التفكير، التي يسعى البرنامج لتعليمها.

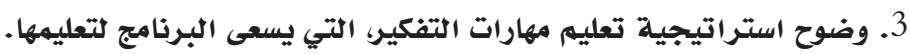

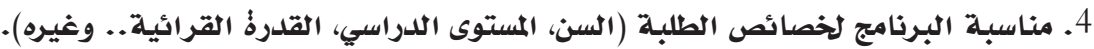

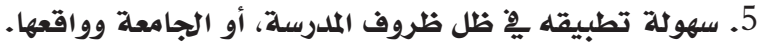

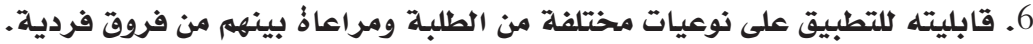

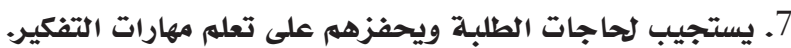

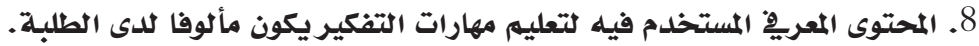

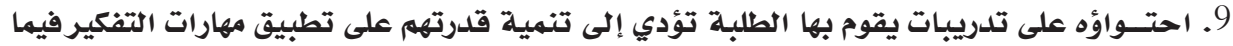

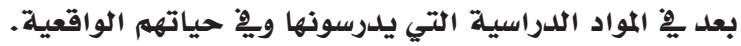

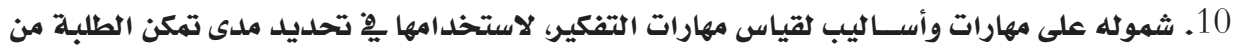

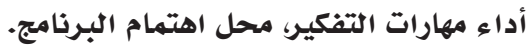

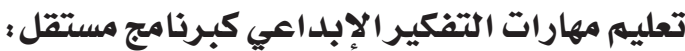

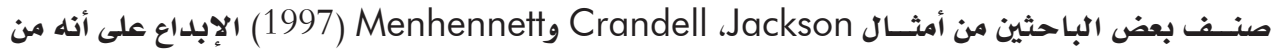

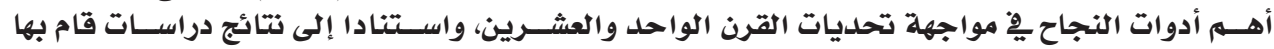

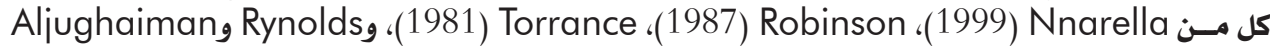

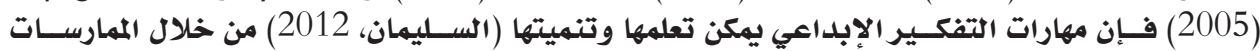

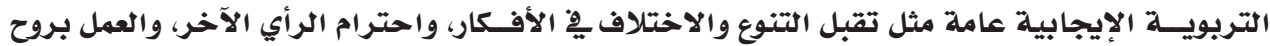

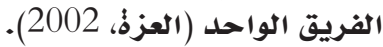

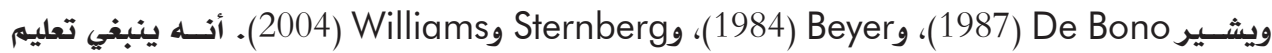

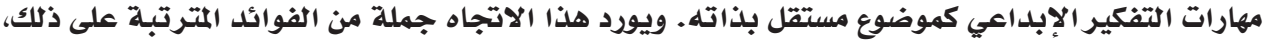

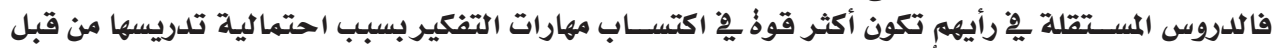

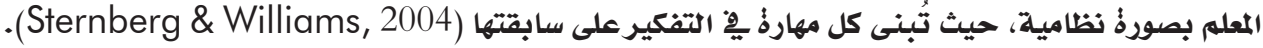

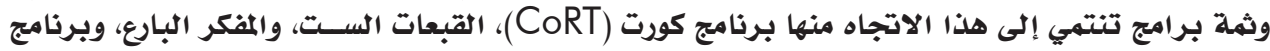

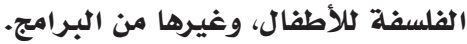

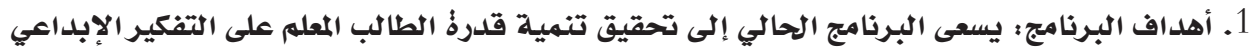

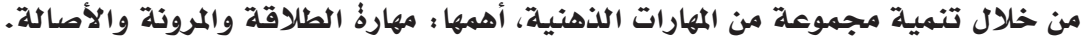

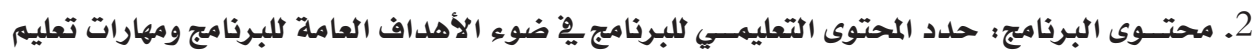

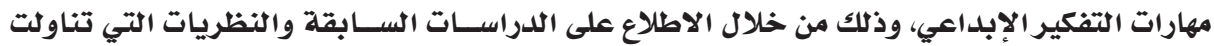
التفكير الإبداعي ومجال طلبة الإبل الجامعة من خلاك (الطالب المعلم). 
3. أنشــطة البرنامج: إن لأهمية الدور الذي تؤديه الأنشــطة التعليمية يِّ العملية التعليمية دورا مهما

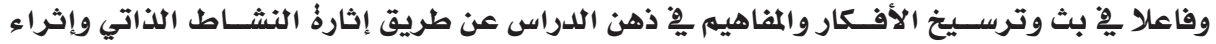

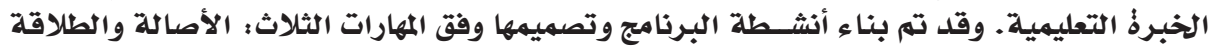

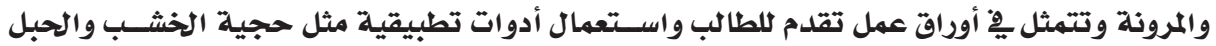

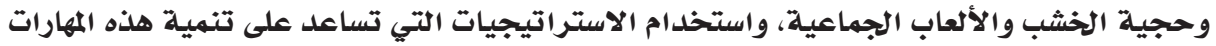
مع مراعاةٌ الأهداف المراد تحاب تحقيقها.

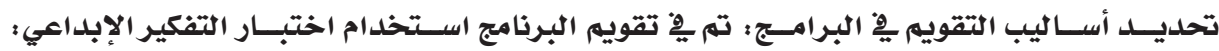

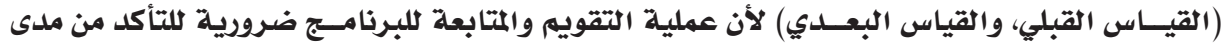

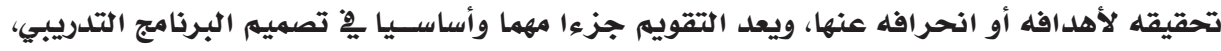

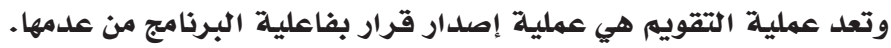

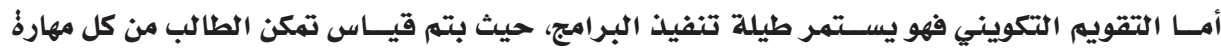

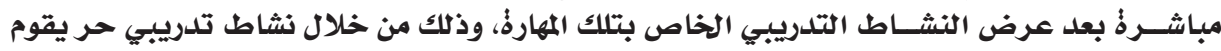

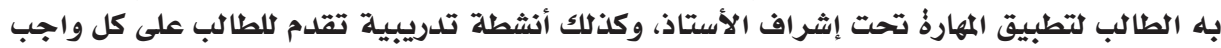
منزلي، يعطى للأستاذ لتقويمه.

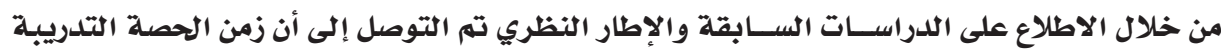

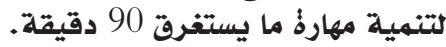

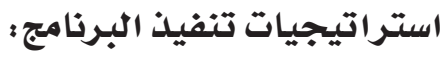

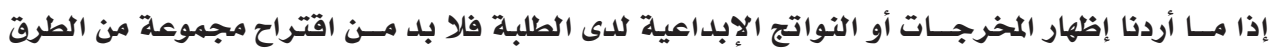

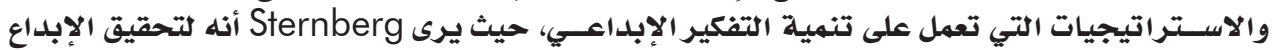

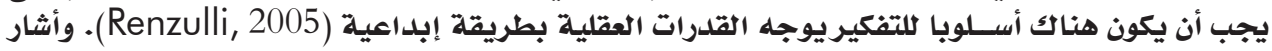
في De Bono

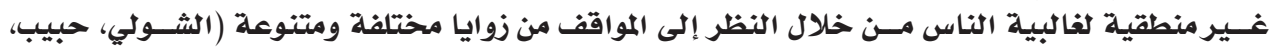

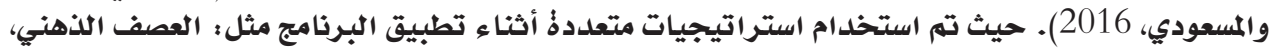

والبحث والاستقصاء، وحل المبكو تمكلات.

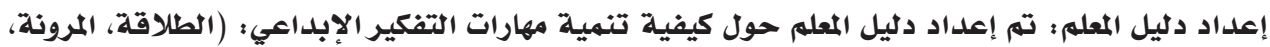
الأصالة)، وقد تضمن محتوى الدادئ إليل على الآتي: - مقدمة.

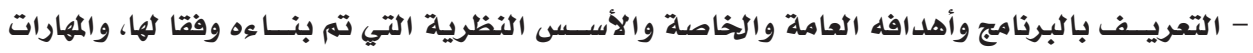

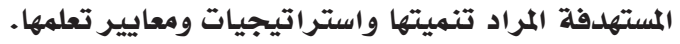
- توجيهات عامة للمعله. - مجموعة من الدروس مقسمة وفة مات أربعة محاور هي كالآتي : • التفكير الإبلاعي (مهاراته واستراتيجيات تعلمه الدوسه).

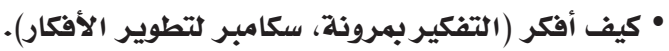

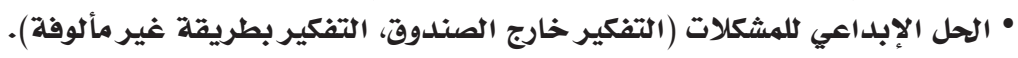

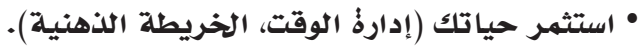

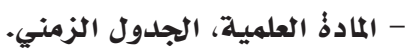

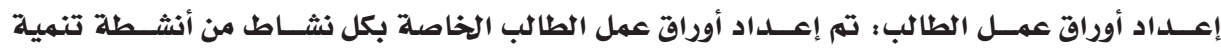

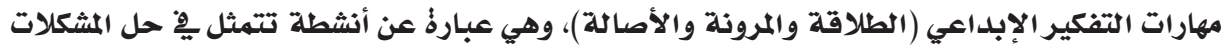

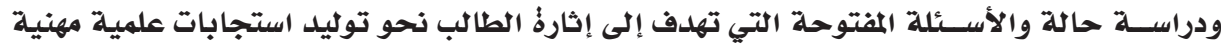

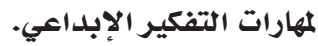




$$
\begin{aligned}
& \text { داود عبد الملك الحلدابي فتيحة العسري } \\
& \text { المجلد الثاني عشر العلدد (22) 2021م المديل }
\end{aligned}
$$

$$
\text { تحكيم البرنامج التعليهي من قبل خبراء }
$$

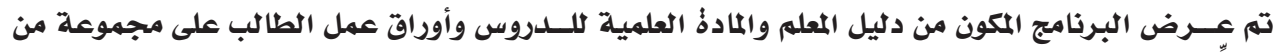

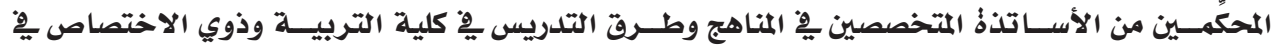

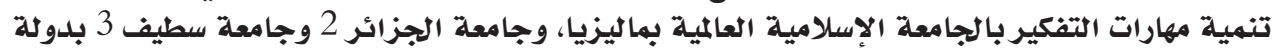

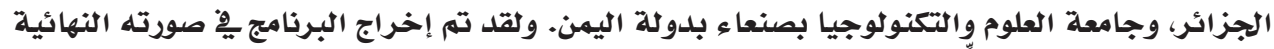
وفقا لآراء الأساتذة المحكمين.

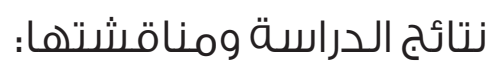

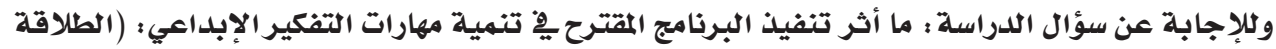

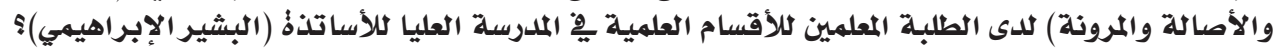
استخدمت الدراسة اختبار(ت) لعينتين مترابطتين لدراسة دلالة الفروق يِّ متوسط التفكير الإبداعي بين

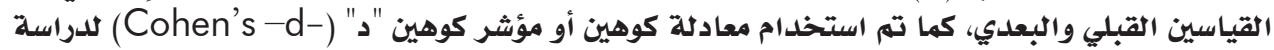

$$
\text { حجم الأثر على العينتين المترابطتين. }
$$

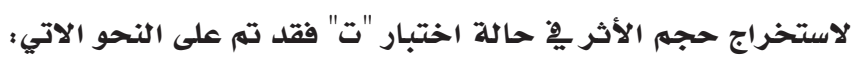

\begin{tabular}{|c|c|}
\hline صغير & قيمة د = 0.2 \\
\hline متوسط & قيمة د = 0.5 \\
\hline كبير & قيمة د = 0.8 \\
\hline
\end{tabular}

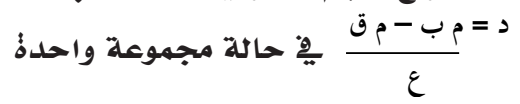

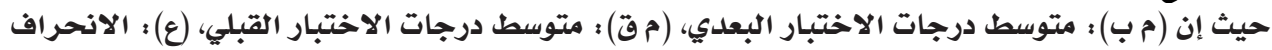

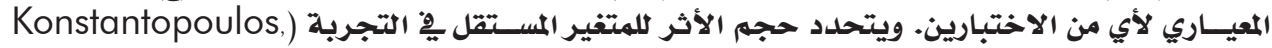

.2008

نتائج اختبار (ت) للتفكير الإبلداعي الكلي ومهاراته : جدول (6) : نتائج تطبيق اختبار(ت) (T. Test) لعينتين مترابطتين لدراسة دلالة الفروق يِّ متوسط التفكير الإبداعي الكلي

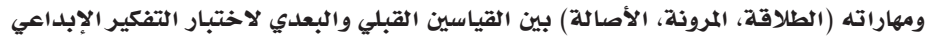

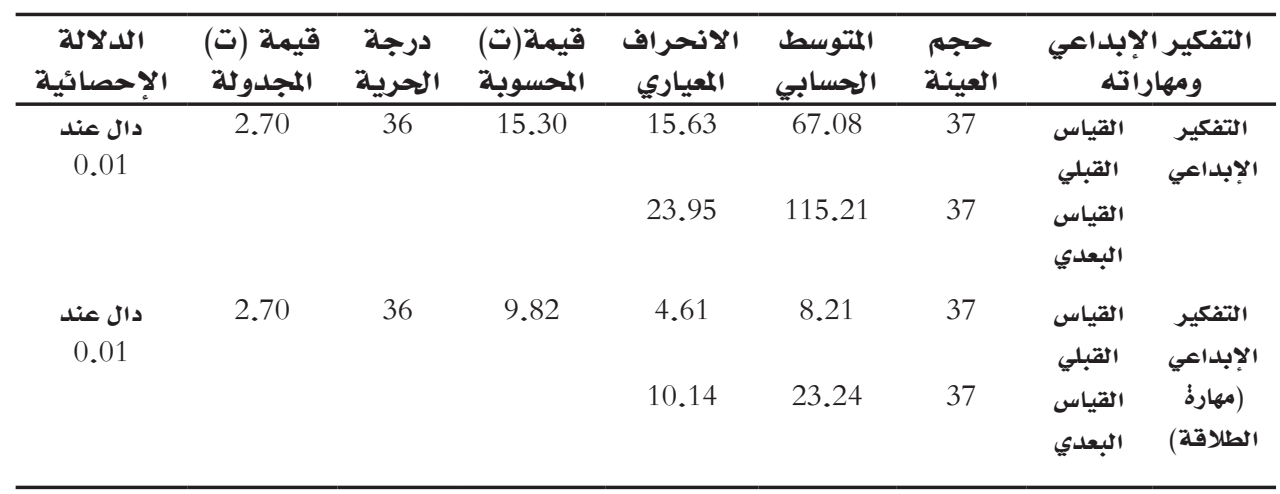


جدول (6) : يتبع

\begin{tabular}{|c|c|c|c|c|c|c|c|c|}
\hline \multirow{3}{*}{ الإحصائية } & \multirow{2}{*}{ قيمة (تلمدلة } & \multirow{2}{*}{ الحرجية } & \multirow{2}{*}{ قالمحسوبة } & \multirow{2}{*}{ الانحياري } & \multirow{2}{*}{ الحتوسط ابلي } & \multirow{2}{*}{ العينة } & \multicolumn{2}{|c|}{ التفكير الإبداعي } \\
\hline & & & & & & & \multicolumn{2}{|c|}{ ومهاراته } \\
\hline & 2.70 & 36 & 10.51 & 4.46 & 21.83 & 37 & القياس & التفكير \\
\hline \multirow[t]{3}{*}{0.01} & & & & & & & القبلي & الإبلداعي \\
\hline & & & & 6.99 & 32.08 & 37 & القياس & (مهارةُ \\
\hline & & & & & & & البعدي & المرونة) \\
\hline \multirow{4}{*}{ دال عند 0.01} & 2.70 & 36 & 11.83 & 11 & 37.62 & 37 & القياس & التفكير \\
\hline & & & & & & & القبلي & الإبداعي \\
\hline & & & & 15.04 & 59.89 & 37 & القياس & (مهارةٌ \\
\hline & & & & & & & البعدي & الأصالة) \\
\hline
\end{tabular}

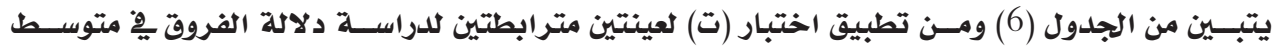

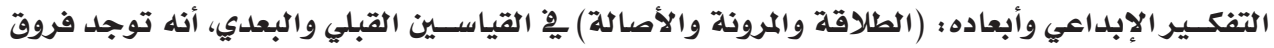

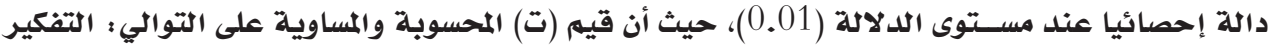

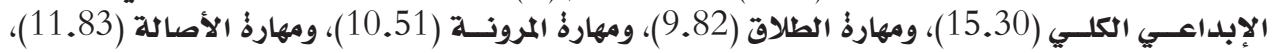

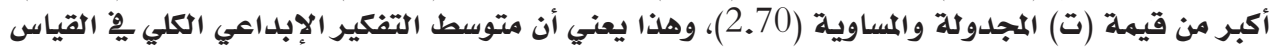

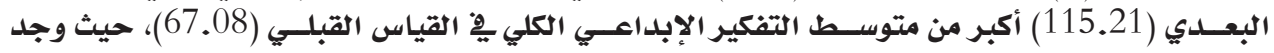
متوسطات درجات الاختبار البعدي دالة إحصائيا (00.00) عند مستوى الإلديس الالة (0.05).

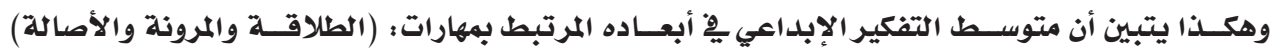

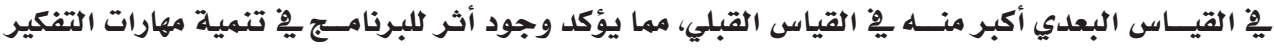

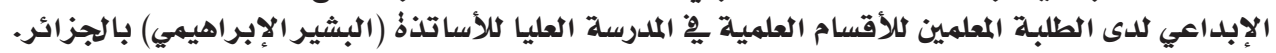

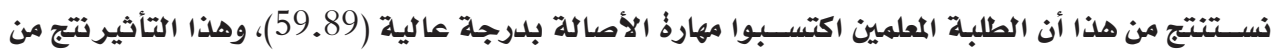

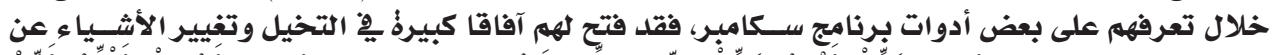

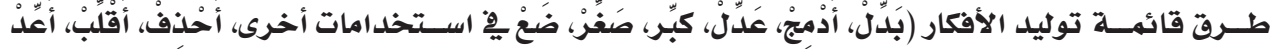

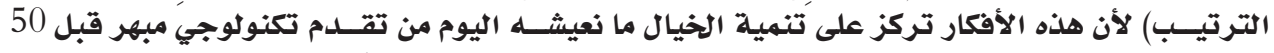

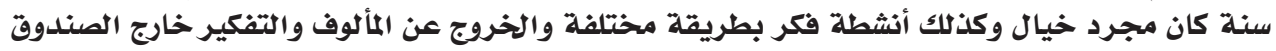

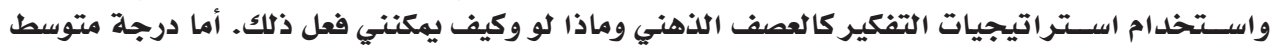

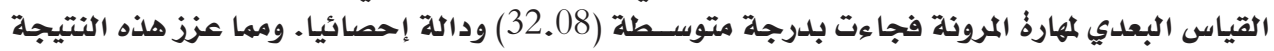

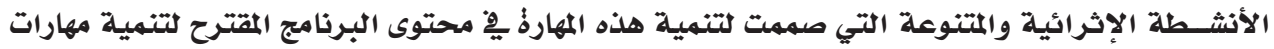

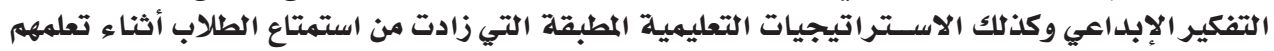

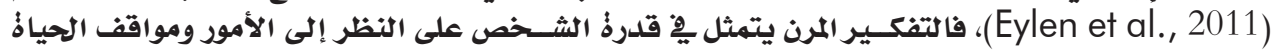

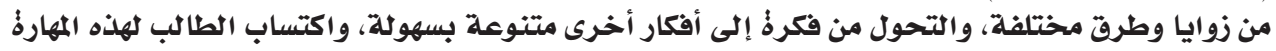

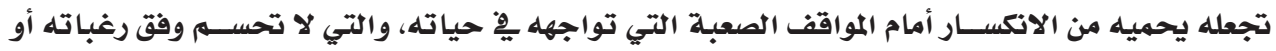

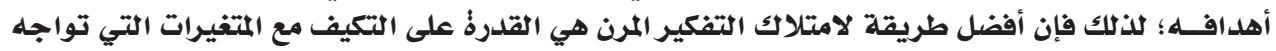

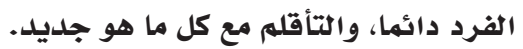

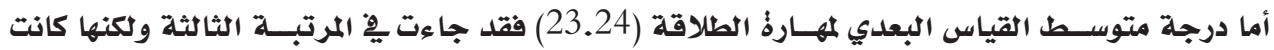

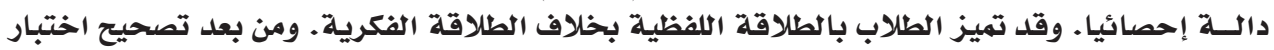

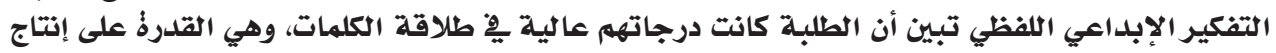

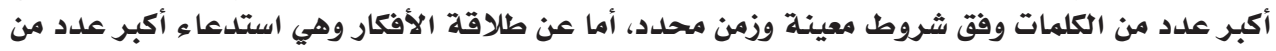

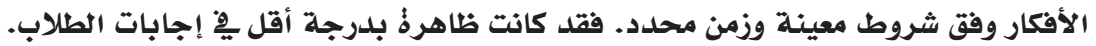




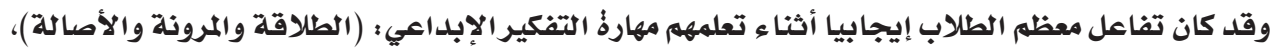

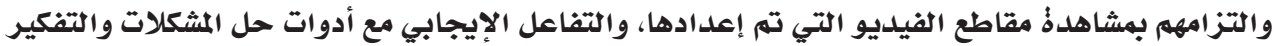

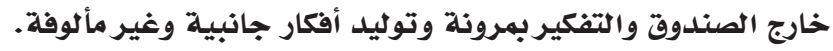

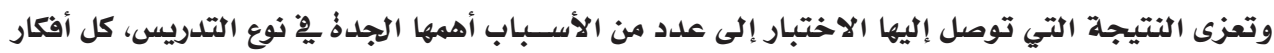

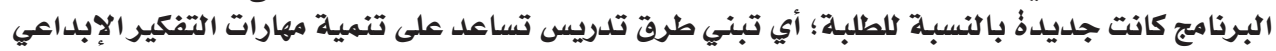

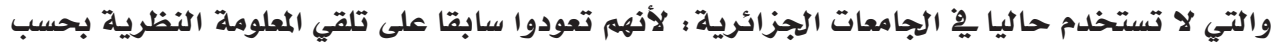

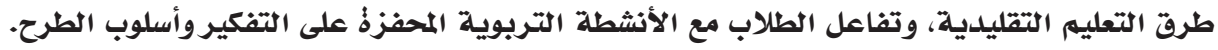

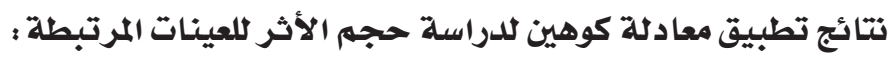

جدول (7): نتائج تطبيق معادلة كوهين للدراسة حجم الأثر للعينات المرتبطة

\begin{tabular}{|c|c|c|c|}
\hline 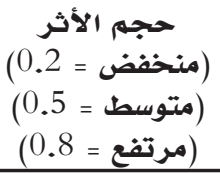 & قيمادلة الأثر حسبن (د) & العينة & التفكير الإبداعي (مهاراته) \\
\hline مرتفع & 2.51 & 37 & التفكير الإبداعي \\
\hline 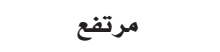 & 1.61 & 37 & التفكير الإبداعي (مهارة الطلاقة) \\
\hline 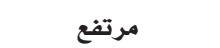 & 1.73 & 37 & التفكير الإبداعي (مهارةٌ المرونة) \\
\hline مرتفع & 1.89 & 37 & التفكير الإبداعي (مهارة الأصالة) \\
\hline
\end{tabular}

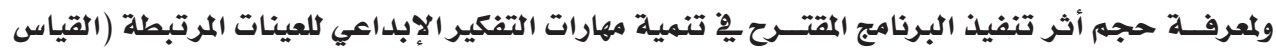

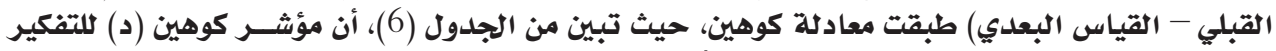

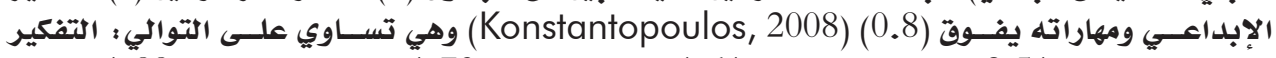

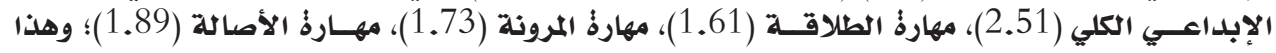
يعني أن حجم أثر تنفيذ البرنامج المقترح لتنمية مهارات التفكير الإبلداعي ومهاراته الته مرتفع.

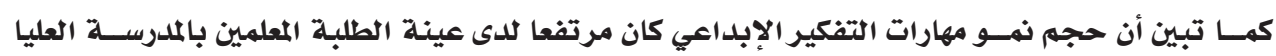

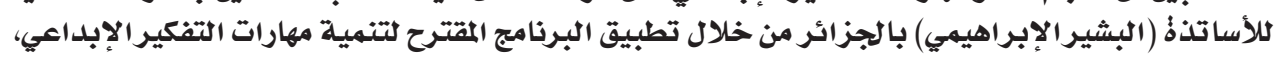

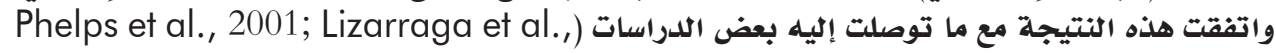

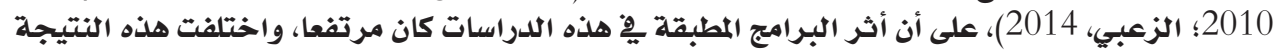

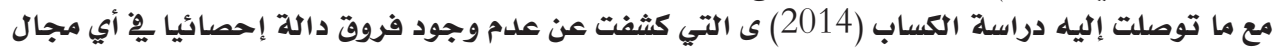

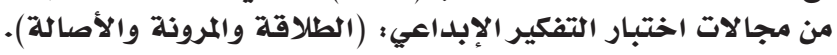

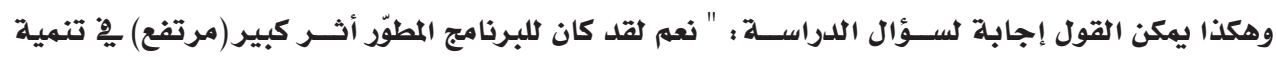

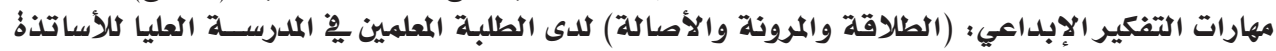

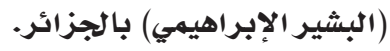

$$
\text { نتائج الدراسة: }
$$

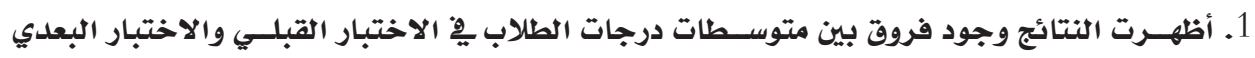

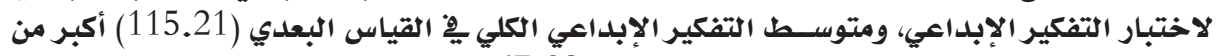

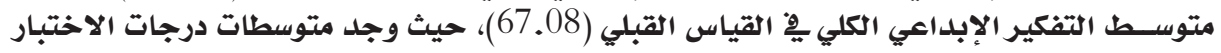

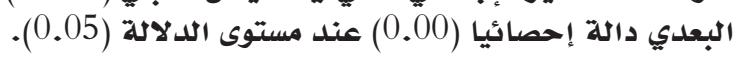

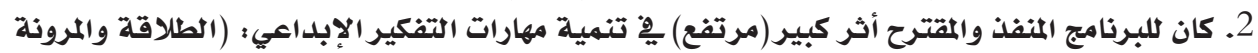

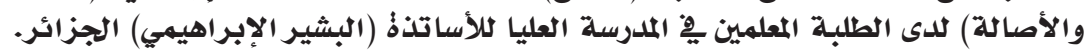


داود عبد الملك الحدابي فتيحة العسري

المجلد الثاني عشر العدد (22) 2021م المئ المرئ

التوصيات:

على ضوء النتائج التي أفرزتها الدراسة، جاءت التواءئ التوصيات على النحو الآتي:

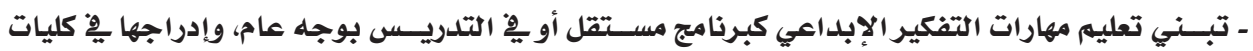

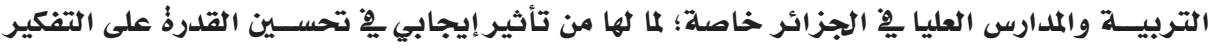

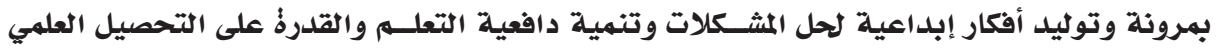

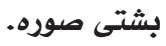

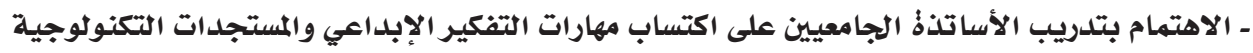

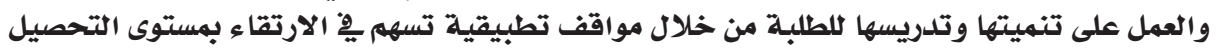

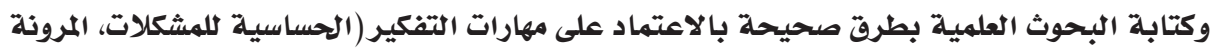

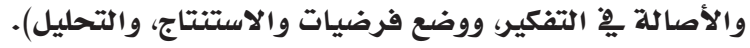

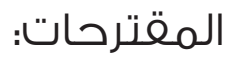

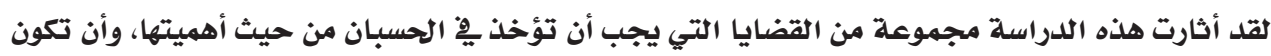

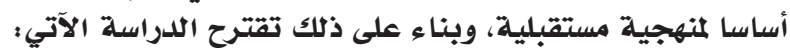
- إجراء دراسات مشابهة على باقي الكليات للوقوف على فاعلية البرنامج المقترح لتتمية مهارات التفكير

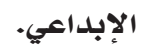

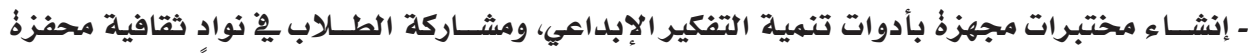
للتفكير من خلال المسابقات فِّ الأنشطة الفكرية يِّ مؤسسات التعليم العالي.

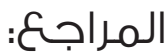

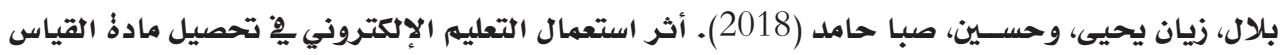

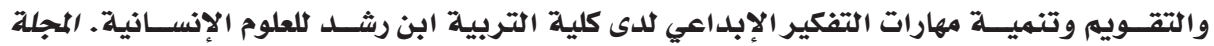

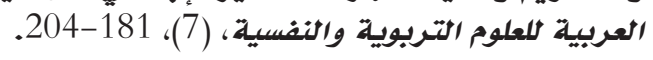

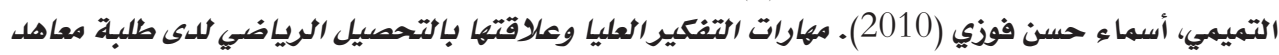

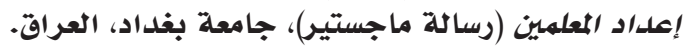

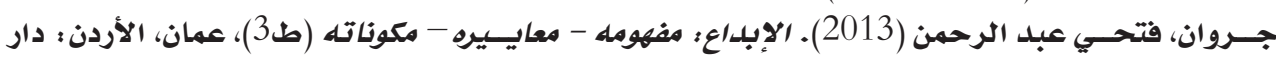

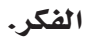

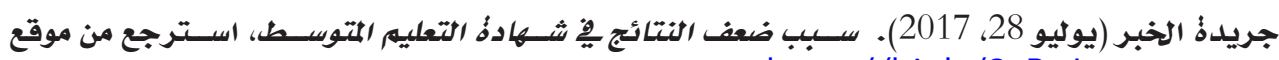

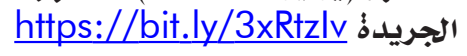

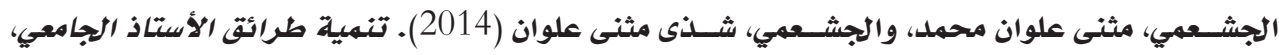

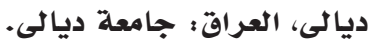

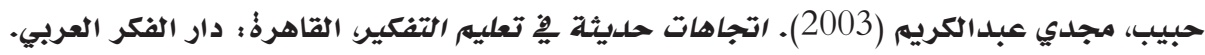

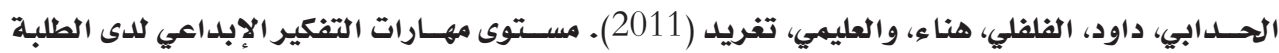

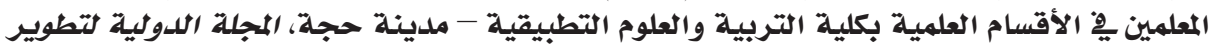

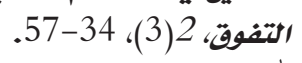

خير الله، سـيد محمد (34)، (1981). علم النفس التريوي: أسسـه النظرية والتجريبية، بيروت: دار النهضة

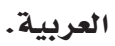

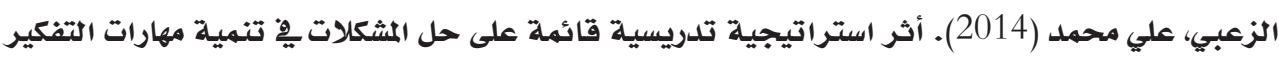

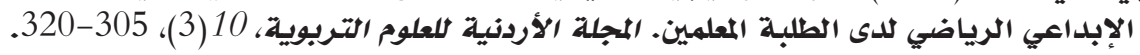


زيتون، حسن حسي (2008). تعليه التفكيرؤية تطبيقية ِِِ تنهية العقول المفكرٌُ (ط4)، القاهرةٌ، مصر :

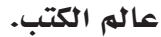

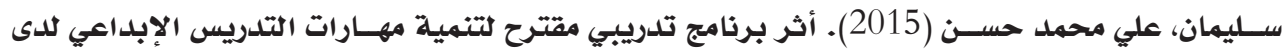

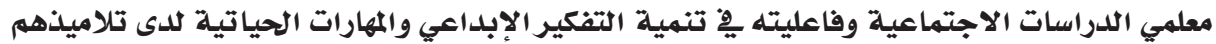

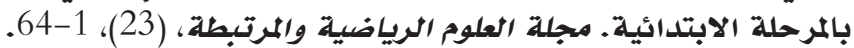

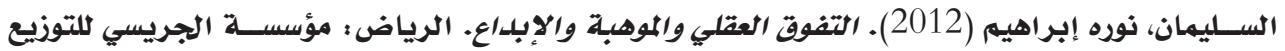

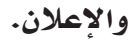

الشولي، فيصل عبد المنشل، حبيب، أمجد عبد الرزاق، والمسعودي، محمد مهدي (2016). أساليب التلدريس الإبلاعي وههاراته (ط1)، عمان، الأردن: دار صفاء آداء للنشر والتوزيع.

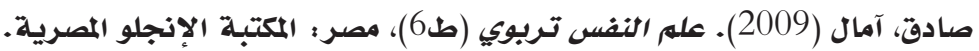

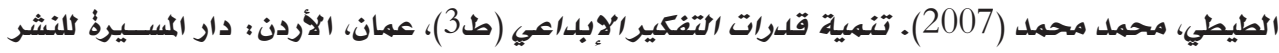

\section{والتوزيع والطباعة.}

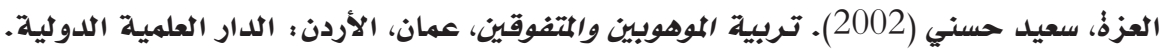

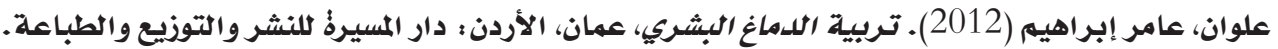

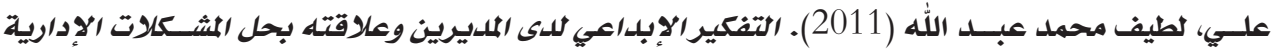

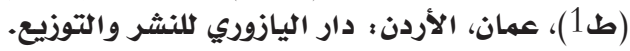

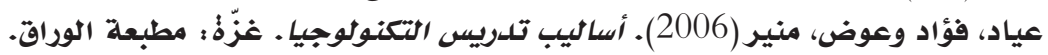

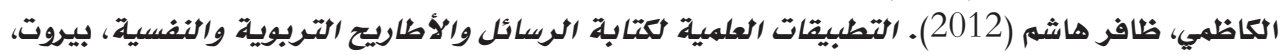

$$
\text { لبنان : دار الكتب العلمية. }
$$

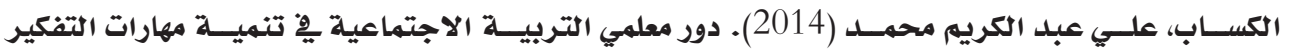

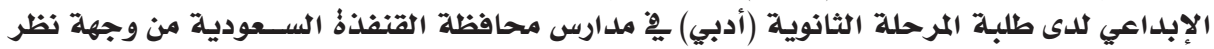

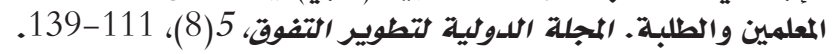

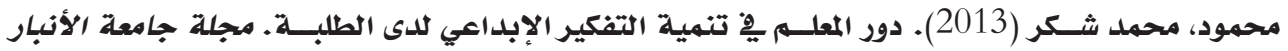

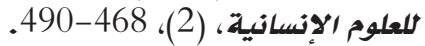

نوفل، محمد بكر، ومحمد قاســـ سـعيفان (2017). تعليم التفكيربين النظريــة والتطبيق (ط6)، عمان، الأردن : دار المسيرةٌ.

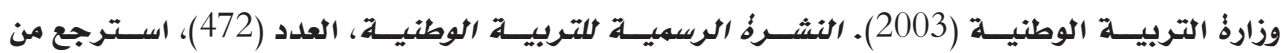
https://bit.ly/3xULBJL

Beyer, B. K. (1984). Improving thinking skills: Practical approaches. The Phi Delta Kappan, 65(8), 556-560.

Clark, B. (2013). Growing up gifted. Columbus: Developing the Potential of Children at School and at Home. Boston, MA: Allyn \& Bacon.

De Bono, E. (1987). CoRT thinking program: Workcards and teacher's notes. Chicago: Science Research Associates.

Eylen, L., Boets, B., Steyaert, J., Evers, K., Wagemans, J., \& Noens, I. (2011). Cognitive flexibility in autism spectrum disorder: Explaining the inconsistencies?. Research in Autism Spectrum Disorders, 5(4), 1390-1401. 
Gregory, E., Hardiman, M., Yarmolinskaya, J., Rinne, L., \& Limb, C. (2013). Building creative thinking in the classroom: From research to practice. International Journal of Educational Research, 62, 43-50.

Kolloff, P. B., \& Feldhusen, J. F. (1984). The effects of enrichment on self-concept and creative thinking. Giffed Child Quarterly, 28(2), 53-57.

Konstantopoulos, S. (2008). The power of the test for treatment effects in threelevel cluster randomized designs. Journal of Research on Educational Effectiveness, 1(1), 66-88.

Lizarraga, M. L. S., Baquedano, M. T. S., \& Rufo, M. P. (2010). Effects of an instruction method in thinking skills with students from compulsory secondary education. The Spanish Journal of Psychology, 13(1), 127-137.

Mils, V., Basset-Séguin, N., Molès, J. P., \& Guilhou, J. J. (1996). 1, 25-Dihydroxyvitamin D3 and its synthetic derivatives MC903 and EB1089 induce a partial tumoral phenotype reversal in a skin-equivalent system. The Journal of Investigative Dermatology, 1(1), 87-93.

Phelps, R., Ellis, A., \& Hase, S. (2001, December). The role of metacognitive and reflective learning processes in developing capable computer users. In the Proceedings of the $18^{\text {th }}$ Annual Conference of the Australian Society for Computers in Learning in Tertiary Education. Melbourne: Biomedical Multimedia Unit.

Renzulli, L. A. (2005). Organizational environments and the emergence of charter schools in the United States. Sociology of Education, 78(1), 1-26.

Ritter, S. M., \& Mostert, N. (2017). Enhancement of creative thinking skills using a cognitive-based creativity training. Journal of Cognitive Enhancement, 7(3), 243-253.

Robinson, I. S. (1987). A Program to Incorporate High-Order Thinking Skills into Teaching and Learning for Grades K-3 (Master thesis). Fort Lauderdale, FL: Nova University.

Robson, L., Stephenson, C., Schulte, P., Amick, B., Chan, S., Bielecky, A., ... \& Grubb, P. (2010). A systematic review of the effectiveness of training \& education for the protection of workers. Toronto: Institute for Work \& Health.

Simonton, D. K. (2010). Creative thought as blind-variation and selectiveretention: Combinatorial models of exceptional creativity. Physics of Life Reviews, 7(2), 156-179.

Sriatun, S., Ellianawati, E., Hardyanto, W., \& Milah, I. L. (2018). Analisis kemampuan berfikir kreatif siswa pada praktikum asas black berbasis problem based learning dan berbantuan makromedia flash [Analysis of students' creative thinking skills in the black principle practicum based on problem based learning and assisted by macromedia flash]. Physics Communication, 2(1), 70-75. 
Sternberg, R. J. (2006). The nature of creativity. Creativity Research Journal, $18(1), 87$.

Sternberg, R., \&. Williams, W. (2004). Educational Psychology. Boston, MA: Allyn \& Bacon.

Torrance, E. P. (1965). Torrance tests of creative thinking: Norms (technical manual). Princeton, NJ: Personnel Press.

Treffinger, D. J., Isaksen, S. G., \& Firestien, R. L. (1983). Theoretical perspectives on creative learning and its facilitation: An overview. The Journal of Creative Behavior, 17(1), 9-17.

Wallas, G. (1926). The art of thought. London: Cape.

\section{Arabic References in Roman Scripts:}

Al-Azza, Saeed Hosni (2002). Tarbiat almawhubin walmutafawiqina, Amman, Al-'Urduni: Aldaar Aleilmiat Aldawliatu.

Al-Hidabi, Daoud, Al-Felfeli, Hana, wa Al-Alimi, Taghreed (2011). Mustawaa maharat altafkir al'iibdaeii ladaa altalabat almuealimin fi al'aqsam aleilmiat bikuliyat altarbiat waleulum altatbiqiat - madinat hajata, Almajalat Aldawliat Litatwir Altafawuqi, 2(3), 34-57.

Ali, Latif Muhammed Abdullah (2011). Altafkir al'iibdaeiv ladaa almudirin waealaqatih bihali almushkilat al'iidaria (Taba'a 1), Amman, Al-'Urdun: Dar Alyazuri Lilnashr Waltawziei.

Al-Jashami, Muthanna Alwan Muhammad, wa Al-Jashami, Shatha Muthanna Alwan (2014). Tanmiat tarayiq al'ustadh aljamieii, Dyalaa, Al-Iraq: Jamieat Dyalaa.

Al-Kassab, Ali Abdel-Karim Mohamed (2014). Dawr muealimi altarbiat alaijtimaeiat fi tanmiat maharat altafkir al'iibdaeii ladaa talbat almarhalat althaanawia ('adbi) fi madaris muhafazat alqanfadhat alsaeudiat min wijhat nazar almuealimin waltalabata. Almajalat Alduwaliat Litatwir Altafawuqi, 5(8), $111-139$.

Al-Kazemi, Dhafer Hashem (2012). Altatbiqat aleilmiat likitabat alrasayil wal'atarih altarbawiat walnafsiati, Bayrut, Lubnanu: Dar Alkutub Aleilmiati.

Al-Shouli, Faisal Abdel-Moneshed, Habib, Amjad Abdel-Razzaq, wa Al-Masoudi, Muhammad Mahdi (2016). 'Asalib altadris al'iibdaeii wamuharatih (Taba'a 1), Amman, Al-'Urdunu: Dar Safa' Lilnashr Waltawziei.

Al-Sulaiman, Norah Ibrahim (2012). Altafawuq aleaqliu walmawhibat wal'iibdaei. Alrayadi: Muasasat Aljirisi Liltawzie Wal'iielani. 
داود عبد الملك الحدابي فتيحة العسري

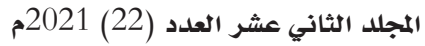

Al-Tamimi, Asma Hassan Fawzy (2010). Maharat altafkir aleulya waealaqatiha bialtahsil alriyadii ladaa talbat maeahid 'iiedad almuealimin (Risalat majistir), Jamieat Baghdad, Al-Iraq.

Al-Titi, Muhammad Muhammad (2007). Tanmiat qudrat altafkir al'iibdaeii (Taba'a 3), Amman, Al-'Urdunu: Dar Almasirat Lilnashr Waltawzie Waltibaeati.

Alwan, Amer Ibrahim (2012). Tarbiat aldimagh albashari, Amman, Al-'Urdun: Dar Almasirat Lilnashr Waltawzie Waltibaeati.

Al-Zoubi, Ali Muhammad (2014). 'Athar astiratijiat tadrisiat qayimat ealaa hali almushkilat fi tanmiat maharat altafkir al'iibdaeii alriyadii ladaa altalabat almuealimina. Almajalat Al-'Urduniyat Lileulum Altarbawiati, 10(3), 305320.

Ayyad, Fouad and Awad, Mounir (2006). 'Asalib tadris altiknulujya. Ghaza: Matbaeat Alwaraqi.

Bilal, Zayan Yahya, wa Hussein, Saba Hamed (2018). 'Athar aistiemal altaelim al'iiliktrunii fi tahsil madat alqias waltaqwim watanmiat maharat altafkir al'iibdaeii ladaa kuliyat altarbiat aibn rushd lileulum al'iinsaniati. Almajalat Alearabiat Lileulum Altarbawiat Walnafsiati, (7), 181-204.

Habib, Magdy Abdel Karim (2003). Atijahat hadithat fi taelim altafkiri, AlQahira: Dar Alfikr Alearabii.

Jaridat Alkhabar (Yuliu 28, 2017). Sabab duef alnatayij fi shahadat altaelim almutawasiti, Aistarjie min mawqie aljaridat https://bit.ly/3xRtzlv

Jarwan, Fathi Abdel Rahman (2013). Al'iibdaei: mafhumuh - maeayiruh mukawinatuh (Taba'a 3), Amman, Al-'Urdun: Dar Alfikr.

Khairallah, Syed Muhammad (1981). Eilm alnafs altarbawi: 'Asasah alnazariat waltajribiata, Bayrut: Dar Alnahdat Alearabiati.

Mahmoud, Muhammad Shukr (2013). Dawr almuealim fi tanmiat altafkir al'iibdaeii ladaa altalbati. Majalat Jamieat Al'anbar Lileulum Al'iinsaniati, (2), 468-490.

Nofal, Muhammad Bakr, wa Muhammad Qasim Saifan (2017). Taelim altafkir bayn alnazariat waltatbiq (Taba'a 6), Amman, Al-'Urduni: Dar Almasirati.

Sadiq, Amal (2009). Eilm alnafs tarbiwiun (Taba'a 6), Misr: Almaktabat Al'iinjulu Almisriatu.

Suleiman, Ali Muhammad Hassan (2015). 'Athar barnamaj tadribiun muqtarah litanmiat maharat altadris al'iibdaeii ladaa muealimi aldirasat alaijtimaeiat wafaeiliatih fi tanmiat altafkir al'iibdaeii walmaharat alhayatiat ladaa talamidhihim bialmarhalat alaibtidayiyati. Majalat Aleulum Alriyadiat Walmurtabitati, (23), 1-64. 
Wizarat Altarbiat Alwatania (2003). Alnashrat alrasmiat liltarbiat alwataniati, Aleadad (472), Aistarjie min https://bit.ly/3xULBJL

Zeitoun, Hassan Hassi (2008). Taelim altafkir ruyat tatbiqiat fi tanmiat aleuqul almufakira (Taba'a 4), Al-Qahira, Misr: Aalam Alkutub. 